\title{
PATRONES DE COAUTORÍA EN LAS PUBLICACIONES ESPAÑOLAS EN CIENCIAS ECONÓMICAS Y EMPRESARIALES INDEXADAS EN EL SSCI
}

\section{PATTERNS OF CO-AUTHORSHIP IN SPANISH ECONOMIC AND BUSINESS SCIENCE ARTICLES INDEXED IN THE SSCI}

Antonio R. Ramos Rodríguez (Universidad de Cádiz) ${ }^{1}$

María Paula Lechuga Sancho (Universidad de Cádiz) ${ }^{2}$

\section{Resumen:}

La coautoría en las publicaciones de investigación es un claro exponente de colaboración científica. Su estudio a lo largo del tiempo permite conocer la respuesta de los investigadores a los criterios de evaluación que las instituciones públicas establecen para evaluar su rendimiento. Con esta intención, el objetivo general de este trabajo ha sido analizar los hábitos de firma de los investigadores españoles en Ciencias Económicas y Empresariales, en revistas indexadas en el Social Science Citation Index. Concretamente, se ofrecen respuestas a tres cuestiones de investigación relacionadas con el número de autores, la posición en el orden de firma y el papel del autor para la correspondencia. Se han observado importantes cambios a lo largo del tiempo, y diferencias significativas entre el campo de la Economía y las Ciencias Empresariales que pueden ser de interés sobre todo para que los responsables del diseño de los diferentes sistemas de promoción y acreditación tengan una visión más certera de la situación real y del proceso adaptativo que ellos mismos generan en la comunidad científica.

Palabras clave: colaboración científica, coautoría, índice de autoría, orden de firma, autor para la correspondencia

Código JEL: M00 Generalidades.

\section{Abstract:}

Co-authorship in research publications is a clear example of scientific collaboration. Its study over time makes it possible to know the response of researchers to the evaluation criteria that public institutions establish to assess their performance. With this intention, the aim of this study has been to analyze the signature habits of Spanish researchers in Economic and Business Sciences in journals indexed in the Social Science Citation Index. Specifically, it is assessed how academic readers interpret the number and order of authors and designation of "corresponding author" in assigning credit and accountability for scientific research. Important changes over time and significant differences amongst the Economics and Business Sciences field that may be of interest mainly to those responsible for designing the promotion and accreditation systems have

\footnotetext{
${ }^{1}$ rafael.ramos@uca.es, Universidad de Cádiz.

2 paula.lechuga@uca.es, Universidad de Cádiz.

Recibido: 7 de abril de 2020. Aceptado: 9 de junio de 2020.
} 
been observed. This would allow them to have a more accurate view of the real situation and of the adaptive process than they trigger off the scientific community.

Keywords: scientific collaboration, co-authorship, authorship index, authorship order, corresponding author, bibliometric.

JEL Codes: M00 Generalidades.

\section{INTRODUCCIÓN}

La complejidad de la actividad investigadora en cualquier disciplina requiere de la colaboración científica para asegurar el progreso del conocimiento. Esta colaboración supone con frecuencia la participación activa de individuos, equipos e instituciones que, procedentes incluso de varias disciplinas, aportan su saber, habilidades y destrezas desde distintos puntos de vista para complementarse unos con otros. El estudio de las motivaciones, el impacto y las consecuencias de las colaboración científica ha sido un tema de especial interés para los propios investigadores (Cronin, 2001; De Filippo, Morillo, y Fernandez, 2008; González Alcaide y Ferri, 2014; Wang, Xu, Wang, Peng, \& Wang, 2013).

Una expresión tangible y bien conocida de la colaboración científica es la coautoría en las publicaciones científicas, particularmente, en forma de artículos de investigación $y$ ha sido estudiada en numerosas ocasiones con indicadores bibliométricos (Abramo, D’Angelo, y Di Costa, 2019; Glänzel, 2001; Wardil y Hauert, 2015). Además de lo anterior, los investigadores también colaboran en la publicación de sus resultados de investigación con la legítima intención de mejorar su productividad e impacto, así como su reputación. Esta doble finalidad está en numerosas ocasiones ligada a facilitar el acceso a la financiación de sus proyectos de investigación y a obtener el reconocimiento de los sistemas públicos de incentivos y promoción a través de la acreditación. En cierto sentido, éste ha sido uno de los principales motivos que ha generado mayor interés para su estudio.

Particularmente en España, el diseño de los criterios de evaluación de los sistemas de promoción, incentivos y acreditación del profesorado se han ido orientando a reducir la discrecionalidad técnica, diseñando estándares de comparación que no siempre han conseguido ser suficientemente precisos y en muchas ocasiones controvertidos. Así, por ejemplo, las directrices de la Comisión Nacional Evaluadora de la Actividad Investigadora (CNEAI) para la evaluación de los sexenios de investigación en el ámbito de las Ciencias Económicas y Empresariales establecen que un elevado número de autores puede reducir la calificación asignada a una contribución, pero no concreta cuánto es un número elevado. Por otro lado, los criterios de evaluación para la acreditación del profesorado universitario del programa Academia de la Agencia Nacional de Evaluación de la Calidad y Acreditación (ANECA) requiere a los interesados aportar indicios de calidad de sus publicaciones, así como concretar su participación en la investigación cuando haya coautoría lo que implica de forma implícita la valoración de la posición de cada autor en el orden de firma.

A la vista de la discrecionalidad que estos u otros criterios pudieran generar se hace necesario conocer bien el comportamiento de los propios autores y diseñar estándares de comparación procedentes de metodologías cuantitativas y objetivas. Así, los indicadores bibliométricos pueden aportar patrones objetivos que tengan en cuenta la especificidad de cada área de conocimiento. Con esta intención, el objetivo general de este trabajo será analizar los patrones de coautoría de los investigadores españoles en 
Ciencias Económicas y Empresariales, en revistas indexadas en el Social Science Citation Index (SSCI) de la Web of Science (WoS), respondiendo a una batería de cuestiones de investigación que se han agrupado entorno a tres grandes aspectos que permitirán caracterizar los hábitos de firma de las publicaciones científicas en este campo (tabla 1). En particular, estos aspectos están relacionados con el número de autores, el orden de firma y el análisis del papel del autor para la correspondencia ${ }^{3}$.

\begin{tabular}{|c|l|}
\hline \multicolumn{2}{|c|}{ TABLA 1. CUESTIONES DE INVESTIGACIÓN } \\
\hline $\begin{array}{c}\text { Análisis del } \\
\text { número de } \\
\text { autores }\end{array}$ & $\begin{array}{l}\text { ¿Cuál la distribución de frecuencias de artículos por número de autores? } \\
\text { ¿Cuál es el número medio de autores en una publicación? ¿Hay diferencias } \\
\text { significativas entre áreas de conocimiento? ¿Cómo ha evolucionado el } \\
\text { número medio de autores por trabajo? ¿Ha sido igual la evolución en las áreas } \\
\text { de conocimiento más importantes? ¿Cuál es el número medio de autores en } \\
\text { los trabajos de colaboración internacional versus los nacionales? ¿Los } \\
\text { trabajos internacionales obtienen mayor impacto? ¿Los trabajos con mayor } \\
\text { número de autores tienen más impacto académico? }\end{array}$ \\
\hline $\begin{array}{c}\text { Análisis del } \\
\text { orden de firma }\end{array}$ & $\begin{array}{l}\text { ¿Cuál es el patrón más habitual de comportamiento en el orden de firma por } \\
\text { orden alfabético o por orden de contribución? ¿Hay relación entre número de } \\
\text { autores y el orden de firma? ¿Hay diferencias significativas por áreas de } \\
\text { conocimiento? ¿Cómo han evolucionado las prácticas del orden de firma? } \\
\text { ¿Han evolucionado igual en todas las áreas de conocimiento? ¿En los trabajos } \\
\text { de colaboración internacional es más habitual el orden de contribución o el } \\
\text { alfabético? ¿En qué medida en los artículos que no se firman por orden } \\
\text { alfabético el primer autor es más relevante que el último o viceversa? ¿Cómo } \\
\text { ha evolucionado este comportamiento? }\end{array}$ \\
\hline $\begin{array}{c}\text { Análisis del papel } \\
\text { del autor para la } \\
\text { correspondencia }\end{array}$ & $\begin{array}{l}\text { ¿En qué medida el primer autor hace de autor para la correspondencia? ¿Hay } \\
\text { diferencias significativas entre áreas de conocimiento? ¿Cómo ha } \\
\text { evolucionado la posición en orden de firma del autor para la correspondencia? } \\
\text { ¿La evolución ha sido la misma en todas las áreas de conocimiento? ¿En los } \\
\text { trabajos de colaboración internacional es más habitual que el autor para la } \\
\text { correspondencia sea el primer firmante? }\end{array}$ \\
\hline
\end{tabular}

Para abordar las cuestiones anteriores se han calculado una serie de indicadores bibliométricos sobre una colección de artículos de investigación indexados en el SSCI de la colección principal de la WoS, en el área de conocimiento de Ciencias Económicas y Empresariales y en los que, por lo menos, ha participado algún investigador adscrito a cualquier universidad, instituto o centro de investigación español.

Entre otros se han calculado indicadores de producción total y fraccionaria, el índice de autoría o número medio de autores por artículo, indicadores de colaboración y se ha obtenido una clasificación según el criterio del orden de firma, alfabético o por contribución. Además de lo anterior, se ha identificado al autor de correspondencia de cada publicación y se ha analizado su posición entre los firmantes. Los resultados se muestran de forma global para todo el campo y desagregada para las tres áreas de conocimiento más importantes: Business, Economics y Management. Además de lo anterior, se muestra la evolución temporal de estos indicadores, así como sus relaciones con otros aspectos importantes como la productividad, el impacto, la relevancia científica y la internacionalización.

\footnotetext{
${ }^{3}$ Corresponding author en terminología anglosajona.
} 


\section{MARCO TEÓRICO}

\subsection{La colaboración científica y las coautorías}

La publicación de artículos sometidos a procesos de revisión anónima por pares se considera cada vez más un pilar importante para el logro de una carrera sostenida, sólida y exitosa (Smith, 2017; Pfleegor et al., 2019). Para facilitar el proceso, la colaboración se ha convertido desde hace ya tiempo en un catalizador natural para mejorar tanto la calidad como la cantidad de las publicaciones producidas (Jin, 2019). De hecho, para publicar con éxito un artículo en una revista dentro del ámbito de las Ciencias Económicas y Empresariales, muchos profesores se han visto en la necesidad de trabajar conjuntamente con otros académicos, no solo con conocimientos en su mismo ámbito, sino con habilidades diferentes y conocimientos relacionados, e incluso con competencias en el ámbito de la estadística, matemáticas o informática (Mantos y English, 2007; 2008). Así pues, esta transición de la autoría única a la autoría múltiple pone de manifiesto la evolución hacia estrategias de investigación colaborativa (Smith, 2017).

Por consiguiente, se considera que la colaboración es un medio de acelerar el rendimiento de la investigación, sin embargo, como cualquier otro esfuerzo de equipo, ofrece tanto beneficios como desafíos que deben ser abordados si se quieren obtener los mejores resultados (Zutshi et al., 2012). La colaboración también puede ser una labor de investigación paralela de los grupos de diferentes países que aplican los mismos protocolos en varios lugares, o cualquier combinación de las anteriores (Katsouyanni, 2008).

En este contexto, la coautoría, es considerada una de las formas más tangibles y bien documentadas de colaboración científica (Koseoglu, 2016), de hecho, casi todos los aspectos de las redes de colaboración científica pueden ser rastreados confiablemente analizando las redes de co-autoría por medio de métodos bibliométricos (Glanzel y Schubert, 2004).

A tenor de lo anterior, durante la última mitad del siglo $\mathrm{XX}$ se observa una tendencia creciente a la coautoría en los artículos de revistas de Economía (Nowell y Grijalva, 2011), Empresa (Manton y English, 2008) y Dirección de Empresas (Brewis, 2018). Y es que, en general, la cooperación parece tener el potencial para aumentar el rendimiento de la investigación en cuanto al número de publicaciones (Endenich y Trapp, 2016), supone un acceso más fácil a la financiación pública, y una mayor visibilidad e impacto científico del trabajo resultante de colaborar con grupos de investigación de renombre (Larivière et al., 2015). Además, muchos estudios han demostrado que los trabajos de coautoría como medida de colaboración tienden a tener un mayor impacto en cuanto a citación que los trabajos de autoría única (Wuchty, Jones \& Uzzi, 2007), reducen el riesgo de fracaso en su publicación (Piette y Ross, 1992) y son el resultado de un deseo de obtener mayor calidad (Cainelli et al., 2015).

Manton y English (2007) constataron que entre 1960 y 1962 la autoría única era la forma dominante de autoría en las revistas de empresa, si bien en 2000-2002, la doble autoría era la forma dominante de autoría en este tipo de revistas. Incluso el porcentaje de tres o más autores por artículo era superior al de la autoría única en muchas revistas. Recientemente, Mishra y Ramesh (2018) hacen un estudio de la pauta de autoría y el grado de colaboración en la investigación empresarial durante el período 1998-2017 extraído de la base de datos SCOPUS, obteniendo que el promedio de autores por artículo es de 2,18 y el promedio de artículos por autor es de 0,45. También, Nowell y 
Grijalva (2011) llevan a cabo una investigación sobre las tendencias de la coautoría en Economía desde 1985. En el ámbito de la Dirección de Empresas, Koseoglu (2016) estudia el crecimiento y estructura de la red de autores y coautores.

Con el significativo crecimiento de la investigación colaborativa, las principales cuestiones relacionadas con la autoría de trabajos en colaboración, es decir, quién debería ser nombrado autor, en qué orden, en base a qué contribución y con qué responsabilidad, han aumentado en número y complejidad, especialmente cuando en ella participan autores de diferentes disciplinas, países y culturas (Smith, 2017).

\subsection{Número de autores}

En la Ciencia moderna donde se promueve la interdisciplinariedad para resolver problemas científicos y donde la cooperación internacional para la generación de conocimiento se hace cada vez más evidente, es común que la información obtenida y publicada en artículos científicos la realicen múltiples autores (Mishra y Ramesh (2018).

Varios estudios han reportado el incremento en las últimas décadas del número medio de publicaciones en coautoría, junto con el número medio de autores por publicación (Sundling, 2017). Esta colaboración entre científicos genera ventajas al mejorar la calidad del manuscrito y de la Ciencia, pero también puede provocar conflictos por integridad, responsabilidad, reconocimiento y justicia en relación a la inclusión, exclusión u orden de autor en los artículos que se generan. Además, dependiendo de la disciplina y el país, un elevado número de autores puede reducir la calificación asignada a una contribución por los diferentes organismos evaluadores del profesorado universitario y del personal investigador, tal y como ocurre en las publicaciones dentro del ámbito de las Ciencias Económicas y Empresariales en el contexto español (véase la resolución de 14 de noviembre de 2018, de la Comisión Nacional Evaluadora de la Actividad Investigadora -Disposición 16138 del BOE núm. 285 de 2018-).

El número de autores de un trabajo debe estar plenamente justificado por el tema, su complejidad y extensión y debe responder a una participación activa en la elaboración del mismo como director o ejecutor del trabajo. En este sentido, el número injustificado de autores en un artículo reduce sin duda el valor de la autoría per cápita (Jin, 2019).

La media del número de autores por contribución es diferente para cada especialidad. No hay ninguna norma que la establezca, sino que es una práctica aceptada y seguida por los investigadores de cada disciplina, si bien se ha constatado que, en el ámbito de la investigación empresarial, no suelen estar conformados por más de cuatro autores (Rath y Wohlrabe, 2016).

\subsection{Orden de firma}

Si bien el número de artículos publicados se utiliza a menudo como medida de la competencia profesional (Smith y Williams-Jones, 2012), el orden de la autoría de esos artículos puede tener aún más importancia, especialmente cuando esto categoriza el nivel de contribución de los individuos y, como tal, se le otorga más o menos prestigio y responsabilidad (Smith, 2017; Helgesson, 2020).

Aunque en investigaciones previas se ha puesto de manifiesto que no hay una determinación unánime de la importancia de las diferentes posiciones de autoría existen 
una gran variedad de interpretaciones que suelen depender de la disciplina científica a la que pertenezcan los autores (Brand et al., 2015; Cutas y Shaw, 2015; Helgesson y Eriksson, 2019). Generalmente, e independientemente del ámbito de estudio, se infiere que es el primer autor el verdadero artífice (o ha realizado una mayor contribución) de la propuesta y por ende el que siempre sale beneficiado en las citas y en cuestiones de visibilidad (Manton y English, 2007). De hecho, para figurar en ciertas bases de datos, como por ejemplo el Author Citation Index, solo se registra el nombre del primer firmante de una publicación omitiendo el nombre de los demás coautores (GonzálezAlcaide et al., 2017).

Por otro lado, el autor que aparece en último lugar de una contribución científica también parece gozar de una posición privilegiada ya que suele ser considerado como el miembro del equipo de más alto nivel que asistió al trabajo son su experiencia y orientación (Ruíz-Pérez et al., 2014). En este contexto, la importancia y los beneficios de ser el primer e incluso el último autor está ampliamente reconocido en la literatura (Abramo et al., 2019).

Es por todo ello que, uno de los componentes más importantes de la confianza en el mundo académico es la asignación adecuada del crédito de autoría (Safa 2012). Madiba y Dhai (2006, pág. 49) sugieren que tanto la "elegibilidad como el orden de autoría deberían debatirse y decidirse idealmente antes de que se redacte el documento, y que cada autor declare su contribución". Esto es especialmente importante cuando un mismo artículo está conformado por autores de varias disciplinas.

En el ámbito de las Ciencias Económicas y Empresariales no se han encontrado artículos científicos que especifiquen cómo debe ser este orden dentro de esta disciplina, trasladándose este tipo de decisión a un acuerdo entre los coautores o del grupo de investigación (Safa, 2012; Committee on Publication Ethics (COPE) and Good Publication Practice). No obstante, como ponen de manifiesto Marušić et al., (2011), la mayoría de las publicaciones en este ámbito parecen regirse desde hace ya mucho tiempo por un criterio universal para identificar el orden de firma, y, es el orden alfabético de los autores. No obstante, como resultado a largo plazo, si el orden de autoría no se rota, puede impactar negativamente en la carrera de investigación de un individuo y llevar a la tensión dentro del equipo (Zutshi et al., 2012).

Además de todo lo anterior, no hay duda que las presiones para publicar están dando lugar a la inclusión indebida de coautores que han contribuido poco o nada a una obra publicada (Manton y English, 2007), convirtiéndose el orden de autoría en un problema complejo enmarcado en aspectos éticos (Zutshi et al., 2012).

\subsection{Autor de correspondencia}

El orden de las firmas y el autor de correspondencia pueden constituir características bibliográficas que se pueden captar en forma de indicadores para medir el papel que desempeñan los autores y su grado de contribución a la investigación en una disciplina o área determinada (Mattsson et al., 2011), facilitando, un análisis preciso y profundo de las prácticas de colaboración (González-Alcaide et al., 2017). Asimismo, en los trabajos con colaboración internacional, el estudio del orden de las firmas y los autores de correspondencia también puede proporcionar información sobre el dominio y el liderazgo en la investigación, arrojando luz sobre las relaciones entre los países, universidades o departamentos que participan en las actividades de investigación (Schubert y Sooryamoorthy, 2010; Fox, 2018). 
La mayoría de los artículos publicados enumeran una o, rara vez, dos personas a las que debe dirigirse toda la correspondencia relacionada con la investigación. Según Bhandari et al. (2014) el autor que toma la responsabilidad de la correspondencia de un artículo es aquel que ha dirigido el trabajo, el diseño, el contenido y la publicación del estudio y por ende merece crédito por ello (Avula y Avula, 2015), independientemente de su posición en el orden de autoría. No obstante, en la mayoría de las disciplinas se ha observado que, por lo general, el autor de correspondencia suele aparecer el primero en orden de firma, o en menor medida, el último (Mattsson et al. 2011; Mo, Hui-Zhen y Yuh-Shan, 2018).

El responsable de la correspondencia es, además, el que asume el compromiso presente y futuro del manuscrito, como la comunicación con los editores de las revistas durante el proceso de publicación (revisión por pares, y el proceso editorial en general) o facilitar información adicional a otros autores cuando así lo requieran (Fox et al., 2018). Del mismo modo, está obligado a asegurarse de que todos los requerimientos logísticos y administrativos tales como detalles sobre la autoría, aprobación de los comités de ética e investigación, el registro de los datos de la investigación y definición de posibles conflictos de interés se cumplan (Duffy, 2017).

En definitiva y como muestran Fox et al., (2018) el orden de firmas o el autor de correspondencia pueden proporcionar información muy pertinente que puede enriquecer cualquier análisis del papel que desempeñan los diferentes participantes en las publicaciones científicas y de las interacciones establecidas en la labor de investigación colaborativa.

\section{METODOLOGÍA}

Para la realización de este estudio se descargaron los 25.053 registros resultado de la búsqueda de artículos ${ }^{4}$ de investigación publicados en el Social Science Citation Index (SSCI) de la Colección Principal de la Web of Science (WoS), sin limitación temporal, en el Área de Investigación "Business \& Economics" y en los que en el campo “CU=Country” apareciera el término "Spain”. La consulta se realizó el 17 de marzo de 2020.

En terminología de la WoS, las Áreas de investigación constituyen un esquema de categorización de materia que es compartido por todas las bases de datos de la Web of Science y como consecuencia permite identificar, recuperar y analizar documentos de diferentes bases de datos que pertenecen a la misma materia. Estas Áreas de investigación se agrupan en cinco grandes categorías generales, a saber: Arts \& Humanities (Artes y Humanidades); Life Sciences y Biomedicine (Ciencia y Tecnología: Ciencias de la Vida y Biomedicina); Physical Sciences (Ciencia y Tecnología: Ciencias Físicas); Social Sciences (Ciencias Sociales) y Technology (Ciencia y Tecnología: Tecnología).

Dentro de la categoría general Ciencias Sociales se identifican veinticinco Áreas de investigación, entre las que se encuentra Business y Economics, que ha sido la usada para identificar la investigación en Ciencias Económicas y Empresariales en nuestro país.

Una vez descargados los datos en formato de texto se transformaron en un formato operativo para la aplicación BibExcel. A partir de ahí, se confeccionó una base de datos

\footnotetext{
${ }^{4}$ Se descartaron otro tipo de documentos como Notas de investigación, proceedings, revisiones, cartas al autor, etcétera.
} 
con los campos necesarios para el análisis de cada registro. En particular se identificó el título, autores, palabras clave, fuente, año, países participantes, citas recibidas y la información del autor para la correspondencia en aquellos registros de contenían esta información.

En términos generales, este trabajo tiene un alcance descriptivo y por ello se han utilizado el cálculo y representación gráfica de varios indicadores bibliométricos. En particular, se ha calculado el índice de autoría como promedio de autores por artículo y, el índice de colaboración como porcentaje de artículos firmados por más de un autor. Para el análisis del orden de autoría se confeccionaron dos listados, uno en el que aparecía el orden de firma original de cada artículo y otro con el orden alfabético. Posteriormente, se confecciono un algoritmo en Excel para comparar ambos listados y se clasificaron los artículos según estuviesen firmados por orden alfabético o por orden de contribución. Para la estimación de la relevancia científica de los investigadores se calculó el índice h (Hirsch, 2005), utilizando la aplicación BibExcel (Persson et al., 2009), a partir del listado total de autores participantes y las publicaciones y citas recibidas en las WoS. Por último, se utilizaron tablas dinámicas de Excel para confeccionar las tablas de frecuencias y las series temporales.

\section{RESULTADOS}

Antes de responder a las cuestiones de investigación propuestas, la figura 1 muestra la evolución de la producción de los investigadores españoles en Ciencias Económicas y Empresariales en términos absolutos y relativos. En un total de 894.617 artículos publicados en el Área de investigación Business and Management e indexados en el SSCI, 25.053 fueron aportaciones con alguna participación de investigadores españoles. Como se puede observar, el crecimiento de la producción total y relativa ha sido exponencial desde principios de los 90, si bien se observa un pico en la producción relativa a partir del año 2016, en el que comienza un tramo descendente cuya evolución y causas merecerían ser observadas con detenimiento en los próximos años para evitar una posible pérdida de competitividad.

\section{FIGURA 1. PRODUCCIÓN TOTAL Y RELATIVA DE PUBLICACIONES} ESPAÑOLAS EN CIENCIAS ECONÓMICAS Y EMPRESARIALES

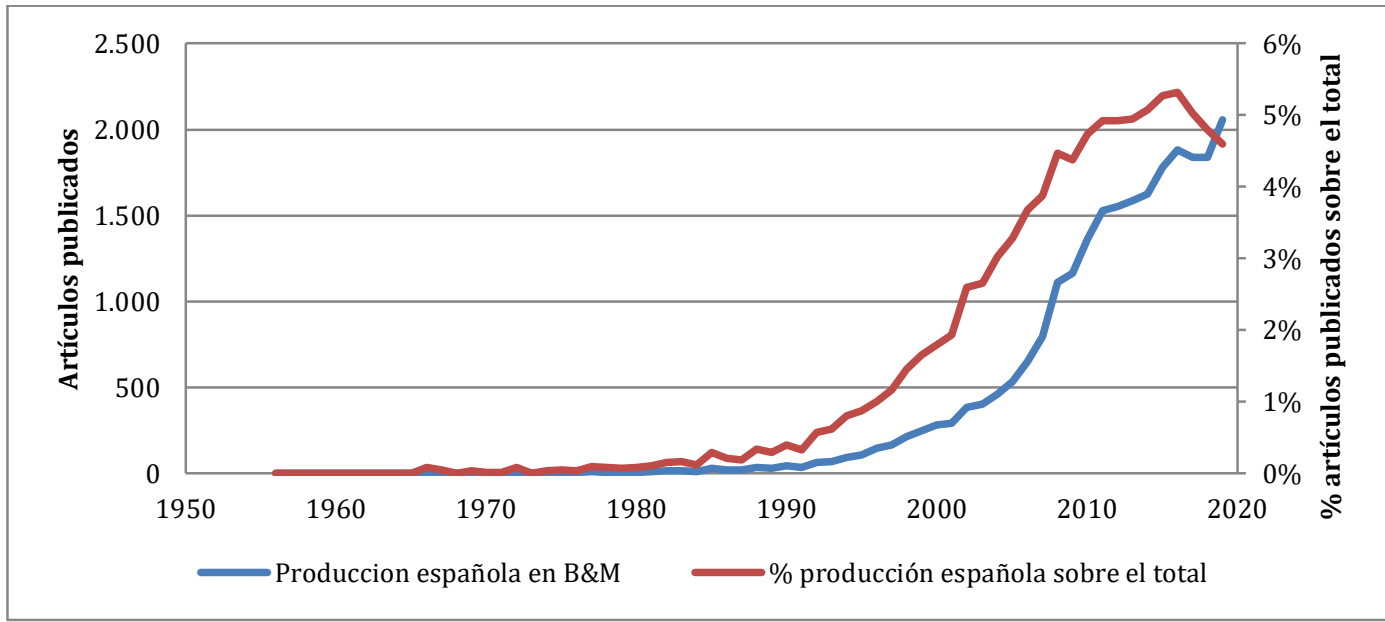

Fuente: Elaboración propia. 
En la colección de trabajos analizados han participado 22.615 investigadores ${ }^{5}$, nacionales o extranjeros, con un volumen de producción media de 2,92 artículos y una productividad fraccionaria ${ }^{6}$ de 0,84 . En relación a cifras globales de impacto se ha observado que el número medio de citas en la WoS por autor ha sido de 58,57, lo que supone, junto a lo anterior, un índice h promedio de cada investigador de 1,82.

\subsection{Cuestión de investigación 1}

En relación al análisis del número de autores por artículo, la figura 2 muestra que sólo un 15,26 por cien de los artículos publicados se han firmado en solitario durante todo el periodo analizado, siendo el resto firmados en colaboración. El número medio de autores por artículo fue de 2,63 y el número más habitual de firmantes en esta Área de investigación sería de dos o tres autores, con un 35,67 por cien y con un 34,51 por cien, respectivamente, del total de artículos publicados. En la colección de artículos analizados han aparecido de forma puntual trabajos firmados por un gran número de autores, en concreto aparece una investigación publicada por 143 autores, otra por 59 autores y cinco más con más de 50 autores. Todas ellas relacionadas con el ámbito de la gestión en Ciencias de la salud, como lo pone de manifiesto las categorías de la WoS de las revistas en las que aparecen publicados, entre otras, Psychology Applied, Psychology, Public Administration, Health Policy \& Services y Environmental Studies. En estas disciplinas es habitual la hiperautoría, pues suelen firmarse por todos los miembros de los equipos de los proyectos y consorcios de investigación que suelen ser amplios y multidisciplinares (Cronin, 2001).

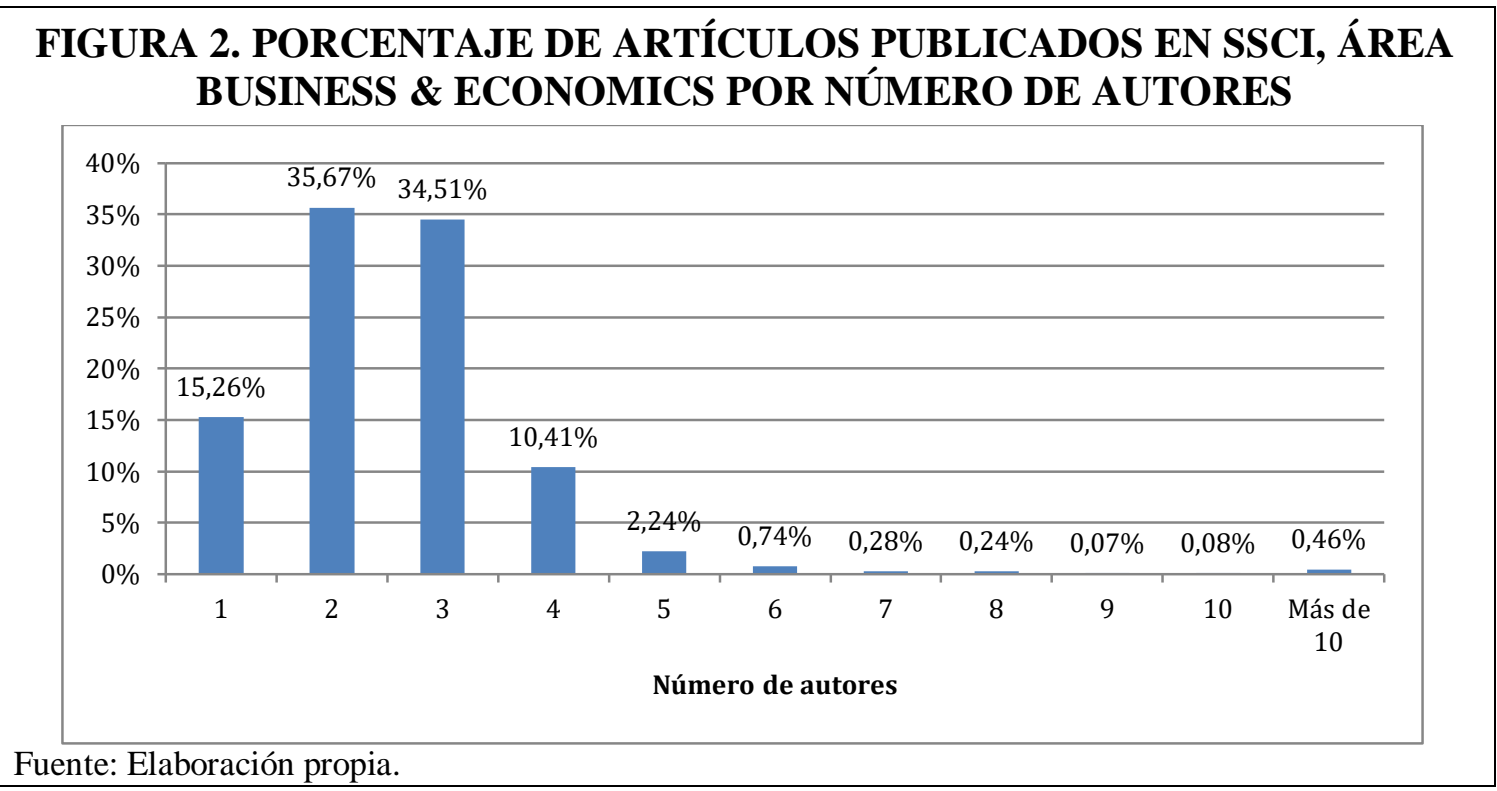

Por agregación de los valores anteriores, se ha calculado el índice de colaboración, como porcentaje de artículos firmado por más de un autor. Este indicador alcanzó un valor promedio para todo el periodo cercano al 85 por cien del total de artículos publicados, con una evolución claramente creciente que alcanza los valores máximos

\footnotetext{
${ }^{5}$ Debido al gran número de inconsistencias en los datos de afiliación de los autores no se ha distinguido entre autores españoles o extranjeros.

${ }^{6}$ La productividad fraccionaria tiene en cuenta la aportación proporcional de cada autor al número de firmantes de cada trabajo.
} 
estos últimos años con valores claramente superiores al 90 por cien (figura 3). Los picos observados en los años 1.975 y 1.982 se deben, simplemente, a que en esos años hubo un número reducido de publicaciones y por ese motivo se genera esa dispersión.

\section{FIGURA 3. EVOLUCIÓN DEL ÍNDICE DE COLABORACIÓN EN BUSINESS \& MANAGEMENT}

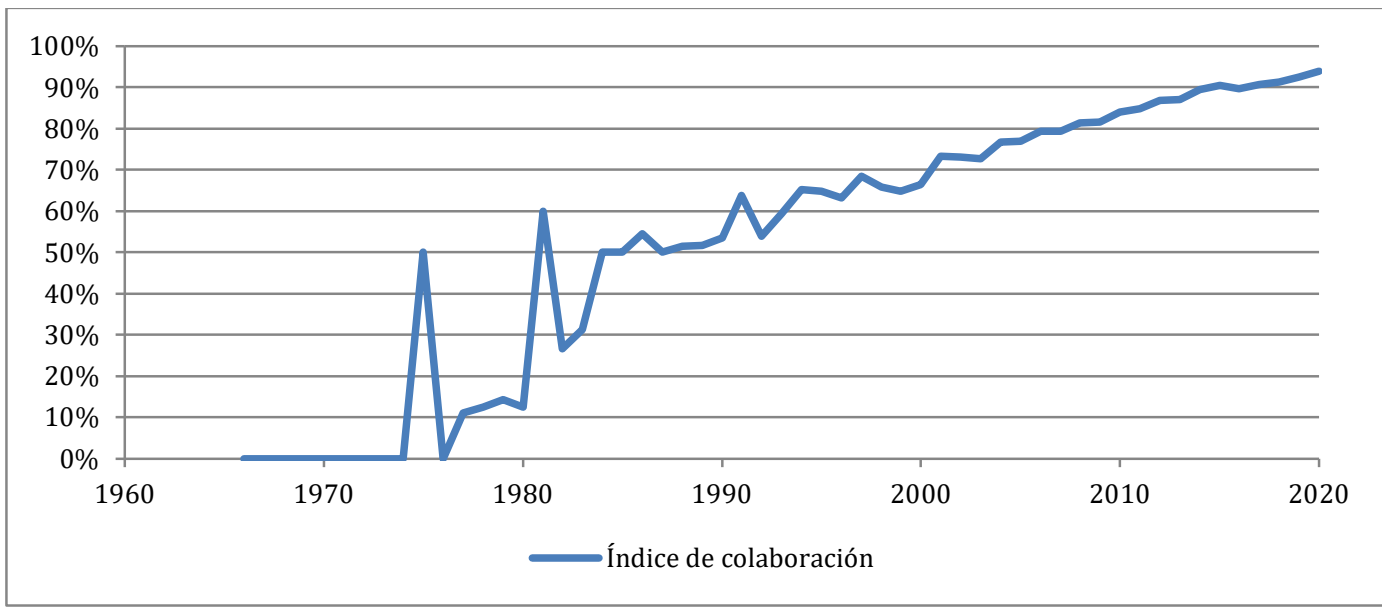

Fuente: Elaboración propia.

La figura 4 muestra la información desglosada para las tres grandes categorías de la WoS incluidas en el Área de investigación analizada. Como se puede observar, hay diferencias notables entre las categorías Business y Management y la de Economic, en la que se observa un menor grado de colaboración en las publicaciones pues casi el 20 por cien de los artículos se han firmado en solitario, mientras que en las dos primeras categorías ronda el 10 por cien. Además de lo anterior, también se puede observar que el número de autores más frecuente en la categoría de Economic es dos, mientras que en Business y Management es de tres autores.

\section{FIGURA 4. PORCENTAJE DE ARTÍCULOS PUBLICADOS EN SSCI POR NÚMERO DE AUTORES EN BUSINESS, ECONOMICS Y MANAGEMENT, 1966-2020}

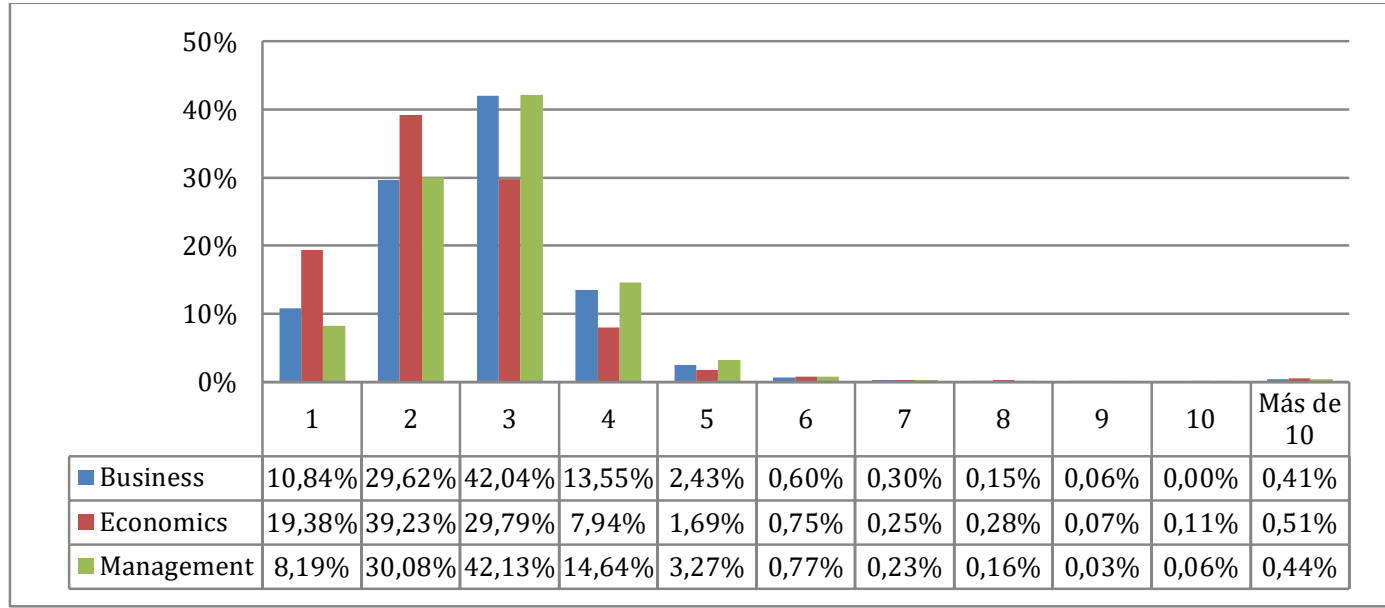

Fuente: Elaboración propia. 
Finalmente, la tabla 2 muestra los índices de autoría o promedio de autores por artículo en estas tres categorías y la figura 5 la evolución del índice de coautoría a partir de mediados de los noventa, en los que el número de publicaciones es mayor, se genera menos dispersión y permite observar mejor las tendencias.

\begin{tabular}{l} 
TABLA 2. ÍNDICE DE AUTORÍA EN BUSINESS, ECONOMICS Y \\
MANAGEMENT, PERÍODO 1966-2020 \\
$\qquad$\begin{tabular}{|c|c|c|}
\hline Número de artículos & Categorías & Índice de autoría \\
\hline 15.109 & Economics & 2,46 \\
\hline 6.969 & Management & 2,91 \\
\hline 5.314 & Business & 2,81 \\
\hline
\end{tabular} \\
\hline
\end{tabular}

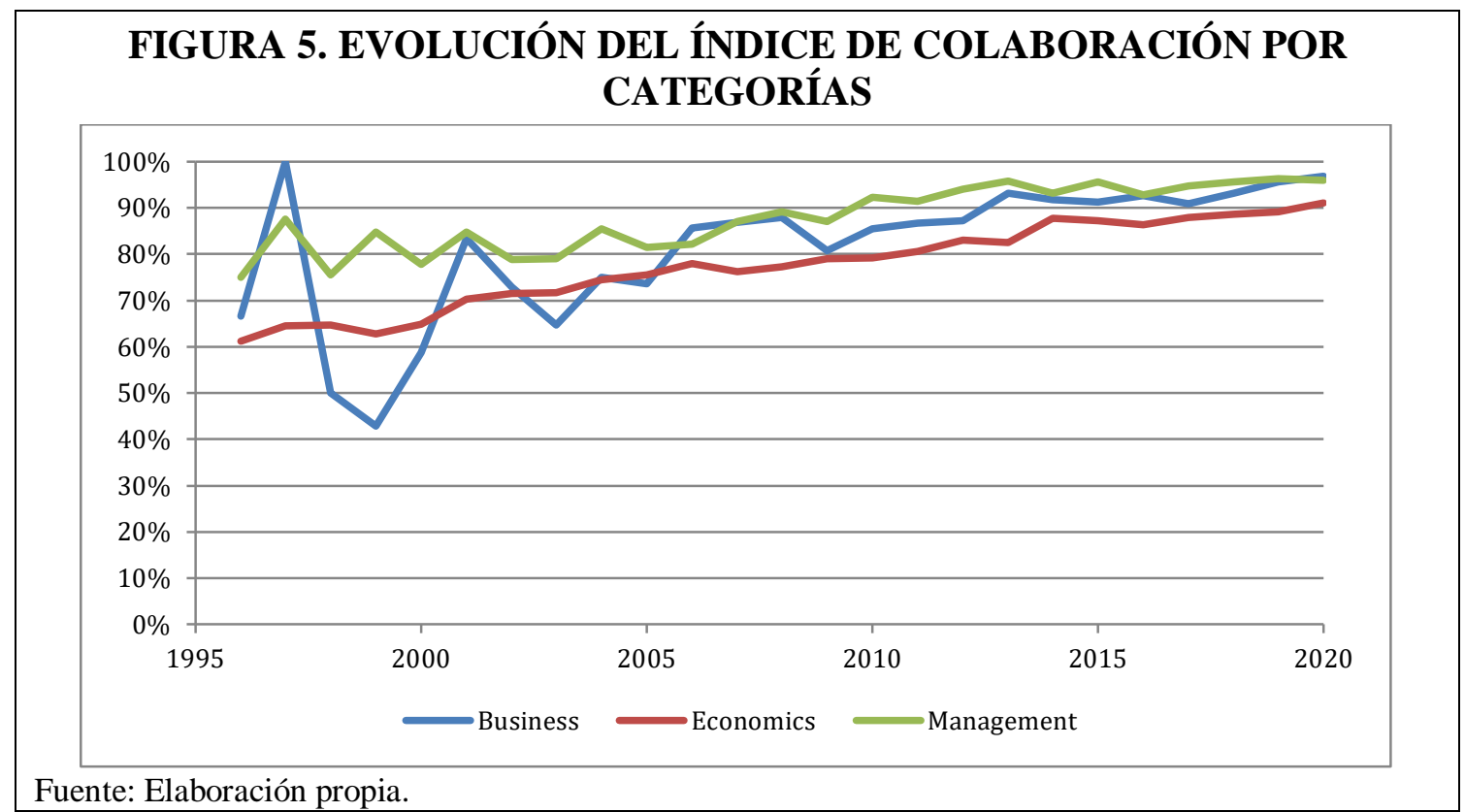

A continuación, se ha analizado la evolución del índice de autoría global a lo largo del período analizado. Como se puede observar en la figura 6, este índice ha seguido una tendencia creciente de forma ininterrumpida desde que se tienen los primeros registros en el SSCI, alcanzando en los últimos años los valores máximos de la serie, en los que se observan valores medios superiores a los tres autores por trabajo. 


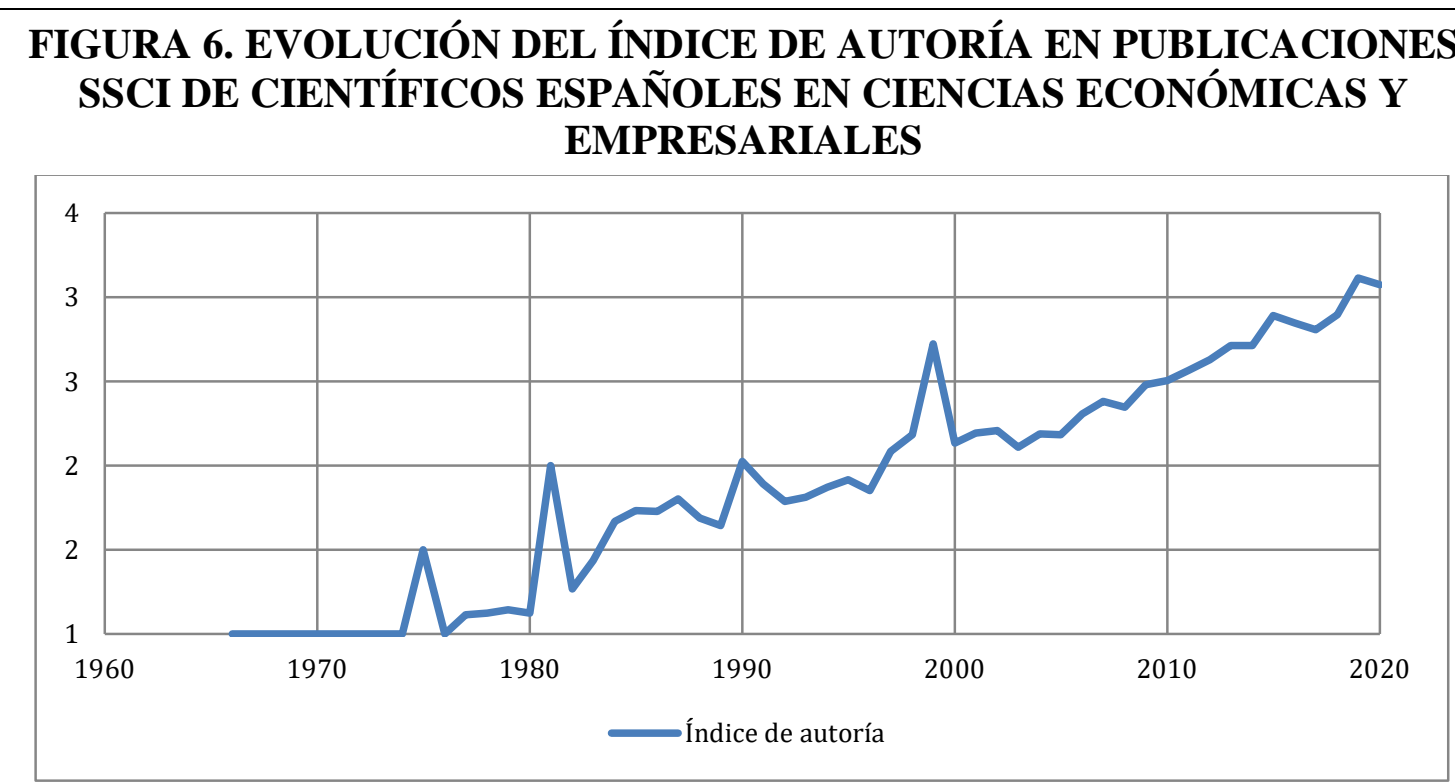

Fuente: Elaboración propia.

La figura 7 muestra el desglose por categoría. Se puede observar como la evolución ha sido pareja en las tres categorías, si bien el número medio de autores por artículo en Economic ha estado, tradicionalmente, por debajo de los de Business y Management. Los picos que se pueden observar en los años 1.999 y 2.001 se deben, fundamentalmente, a la publicación de sendos artículos con un número muy elevado de autores como se comentó en un apartado anterior.

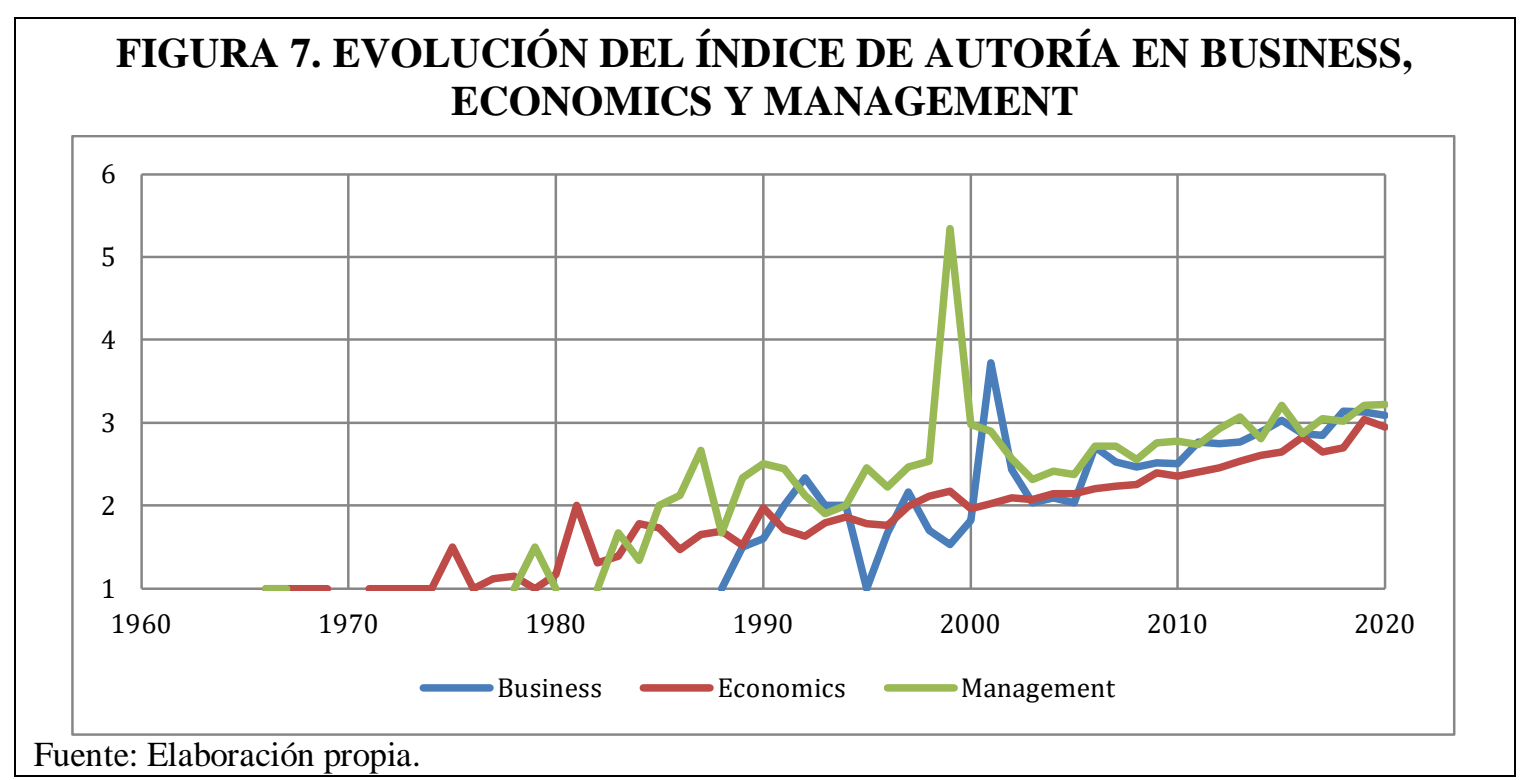

Otro aspecto que ha parecido interesante estudiar es la relación entre el índice de autoría y el nivel de internacionalización de las investigaciones. Como se puede observar en la figura 8, el índice de autoría crece en el mismo sentido que el número de países que participan en cada investigación. En particular, el número medio de autores por artículo en la que sólo participan investigadores españoles en Ciencias Económicas y Empresariales alcanza el valor 2,32, mientras que cuando hay participación, al menos de otro país, este indicador alcanza un valor promedio de 3,08 autores por artículo. 


\section{FIGURA 8. ÍNDICE DE AUTORÍA EN RELACIÓN AL NÚMERO DE PAÍSES PARTICIPANTES EN LA INVESTIGACIÓN}

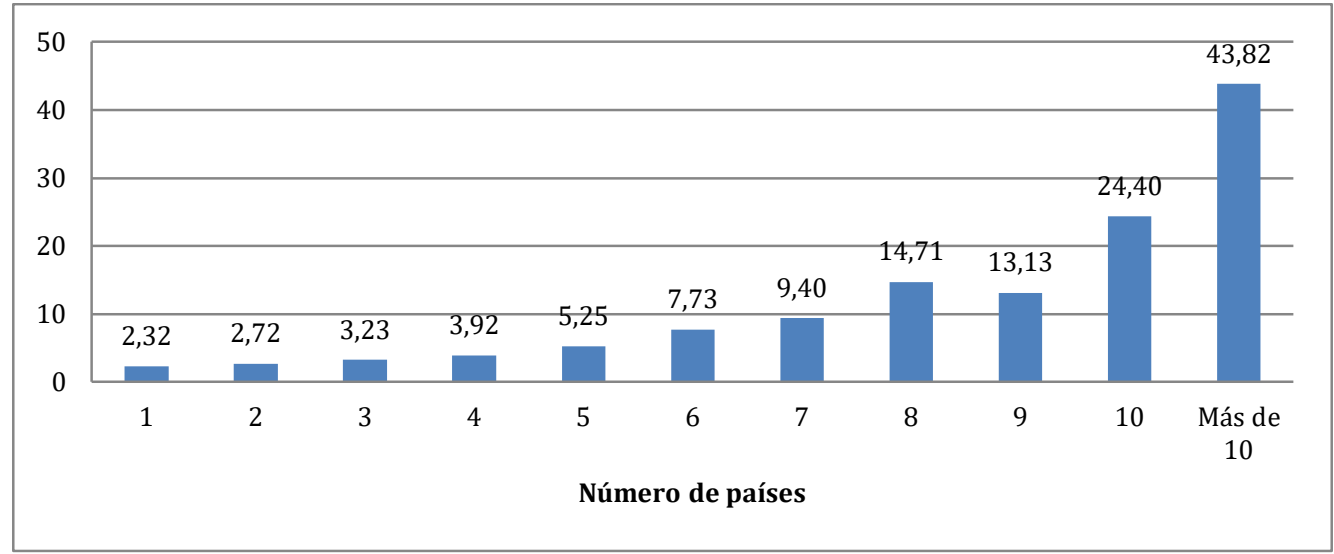

Fuente: Elaboración propia.

Otro aspecto interesante estudiado fue el impacto de los artículos, medido por el número de citas recibidas en la WoS, en relación a la internacionalización de los equipos de investigadores. El número medio de citas recibidas, independientemente de la internacionalización o no de la investigación, se situó en 17,99 citas por artículo. Pero, en particular, como se puede observar en la figura 9, la investigación internacional tiene mayor impacto que la que se realiza de forma autóctona. Así, el número medio de citas que recibe un artículo en Ciencias Económicas y Empresariales realizado solo por autores españoles es de 15,33, mientras que, en promedio, aquellas investigaciones que se realiza en colaboración internacional alcanzan las 21,76 citas en valores promedio.

\section{FIGURA 9. NÚMERO MEDIO DE CITAS RECIBIDAS EN LA WOS EN RELACIÓN A NÚMERO DE PAÍSES PARTICIPANTES}

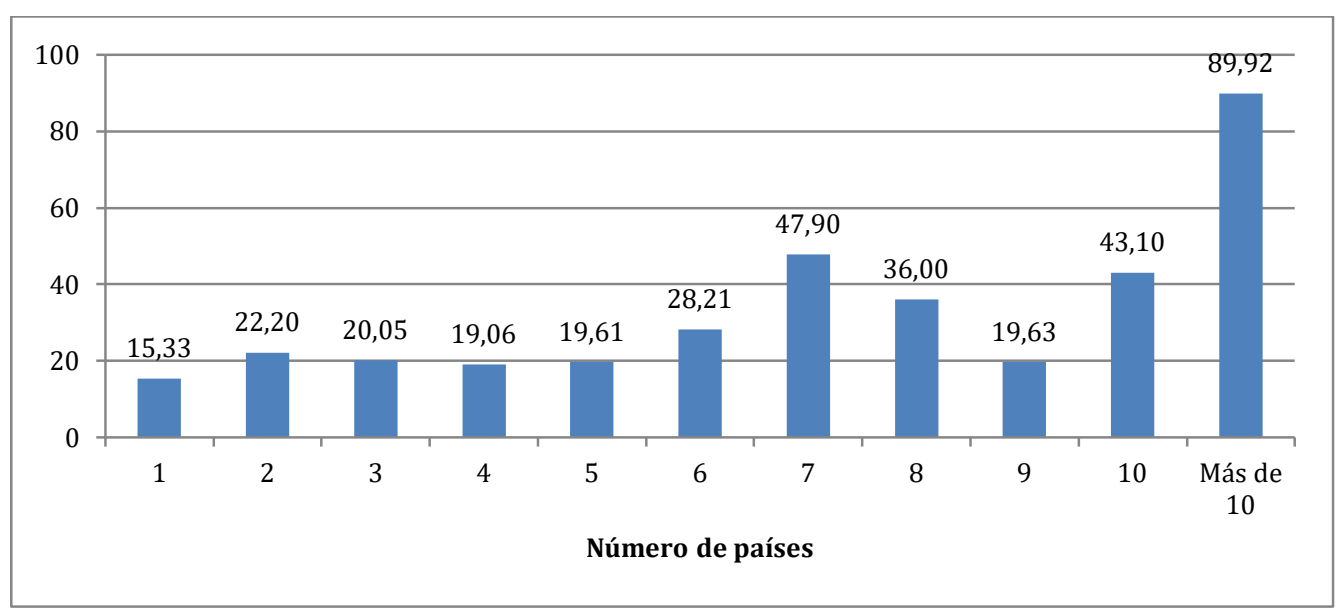

Fuente: Elaboración propia.

Para finalizar, se estudió la relación entre el índice de autoría y el impacto recibido por los artículos, medido también por el número de citas recibidas en la WoS. Como se puede observar en la figura 10, en términos generales, los trabajos en colaboración tienen mayor impacto en la comunidad científica. Así, mientras que un trabajo firmado en solitario tiene un promedio de 14,01 citas, cuando se firma en colaboración se alcanzan valores promedio de 18,70. 


\section{FIGURA 10. RELACIÓN NÚMERO DE AUTORES Y CITAS RECIBIDAS}

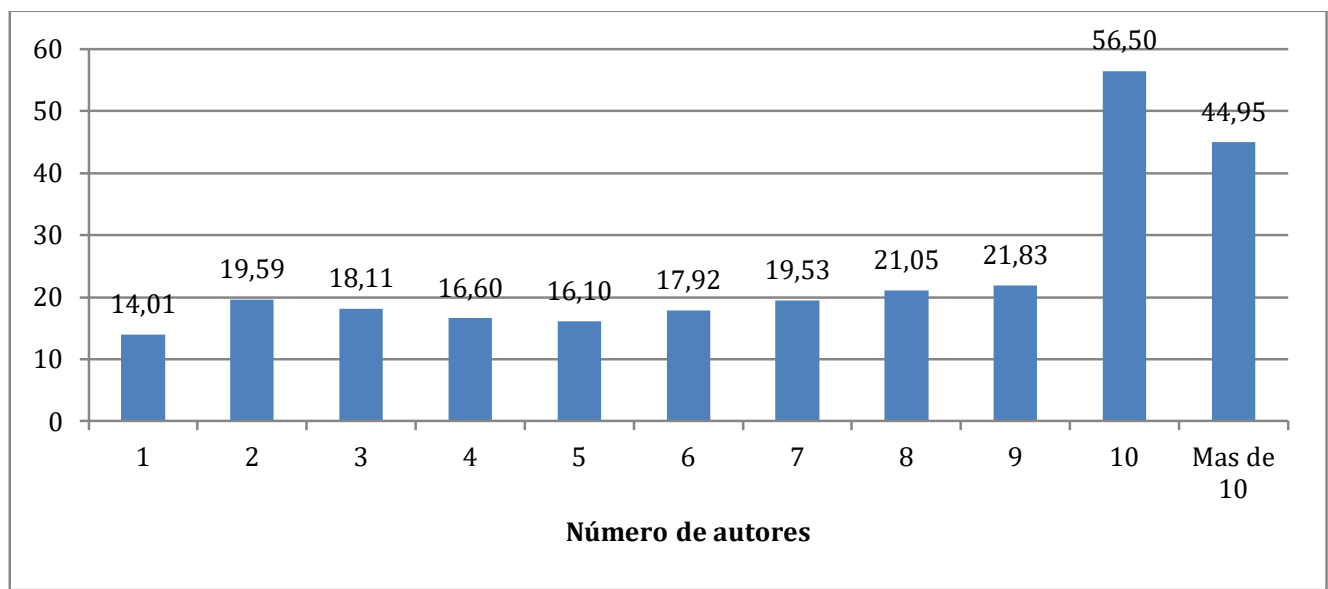

Fuente: Elaboración propia.

\subsection{Cuestión de investigación 2}

El siguiente aspecto analizado fue el orden de firma de los artículos. Para ello, solo se han tenido en cuenta los artículos firmados en colaboración, eliminando del análisis los firmados por un solo autor, y se han distinguido dos modalidades: por orden alfabético y por orden de contribución. Cada vez son más las revistas que incluyen recomendaciones sobre el orden de firma. En términos generales el orden alfabético se utiliza cuando es difícil distinguir la contribución de cada uno de los autores y, además, así se acuerda entre ellos.

En relación a los 21.230 artículos firmados en coautoría, podemos afirmar que el $45,66 \%$ fueron firmados por orden de contribución. Mas detalladamente, como se muestra en la Figura 11, a medida que crece el número de autores también lo hace el porcentaje de firmas por orden de contribución, y de forma significativa, en artículos firmados por 4 o más autores. En el caso de los artículos con dos o tres casos, el análisis puede ser no muy revelador ya que podrían reflejar la mera coincidencia del orden de contribución con el orden alfabético.

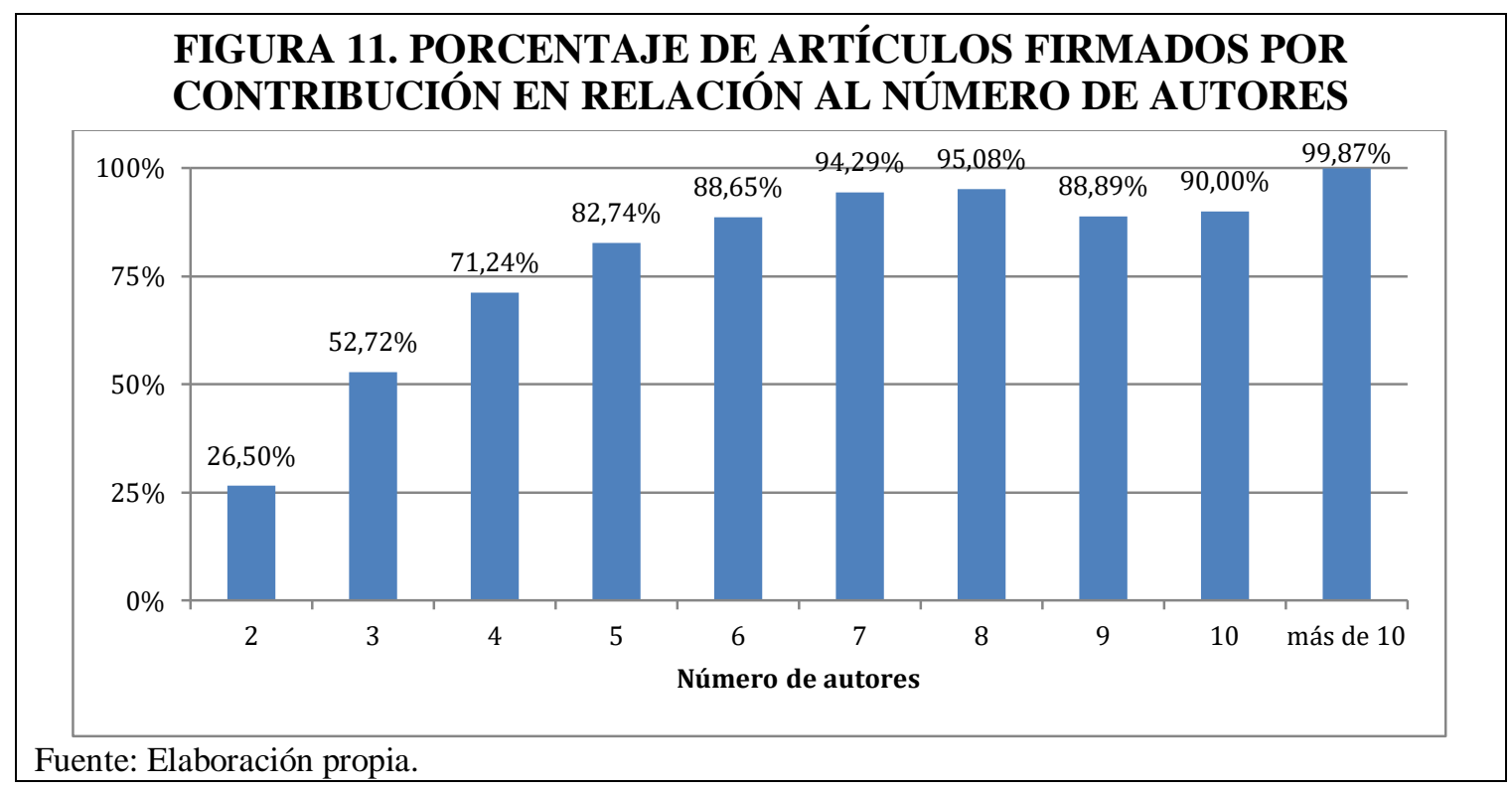


La figura 12 muestra esta información desagregada para las tres categorías más importantes. Como se puede observar, en términos generales, la firma por orden de contribución es menos habitual en la categoría de Economía, que alcanza el 27,64 por cien, frente a las otras dos donde los porcentajes son muy similares y superan, claramente, a la mitad de los artículos publicados.

\section{FIGURA 12. PORCENTAJE DE ARTÍCULOS FIRMADOS POR ORDEN DE CONTRIBUCIÓN EN BUSINESS, ECONOMICS Y MANAGEMENT}

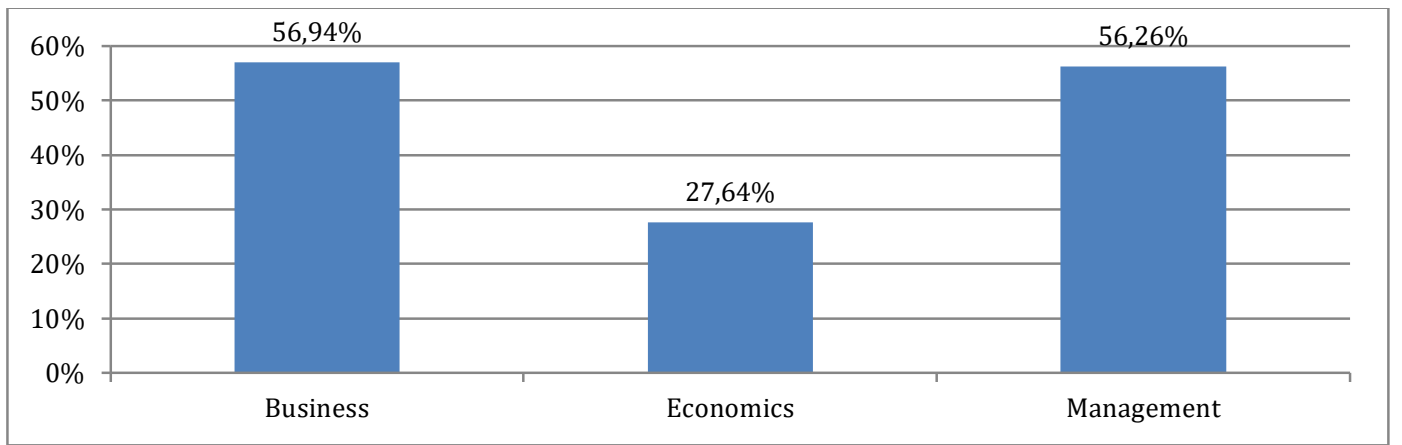

Fuente: Elaboración propia.

Ha parecido interesante también analizar la evolución de este comportamiento a lo largo del tiempo y, como se puede observar en la figura 13, existe una tendencia claramente creciente que lleva a que en la actualidad sean más de la mitad de los artículos los que se firman por orden de contribución en el ámbito de las Ciencias Económicas y Empresariales, en contraposición al orden alfabético. Este comportamiento, seguramente, podría ser la respuesta de los investigadores a que los sistemas de incentivos y acreditación nacional están empezando a tener en cuenta de forma decidida este aspecto, dejando de ser el orden de firma un aspecto intrascendente en la publicación de los resultados de investigación y que permite a los investigadores justificar su grado de contribución a la publicación. Como se comentó anteriormente, los picos observados son debidos al escaso número de publicaciones en esos años.

\section{FIGURA 13. EVOLUCIÓN DEL PORCENTAJE DE ARTÍCULOS FIRMADOS POR ORDEN DE CONTRIBUCIÓN}

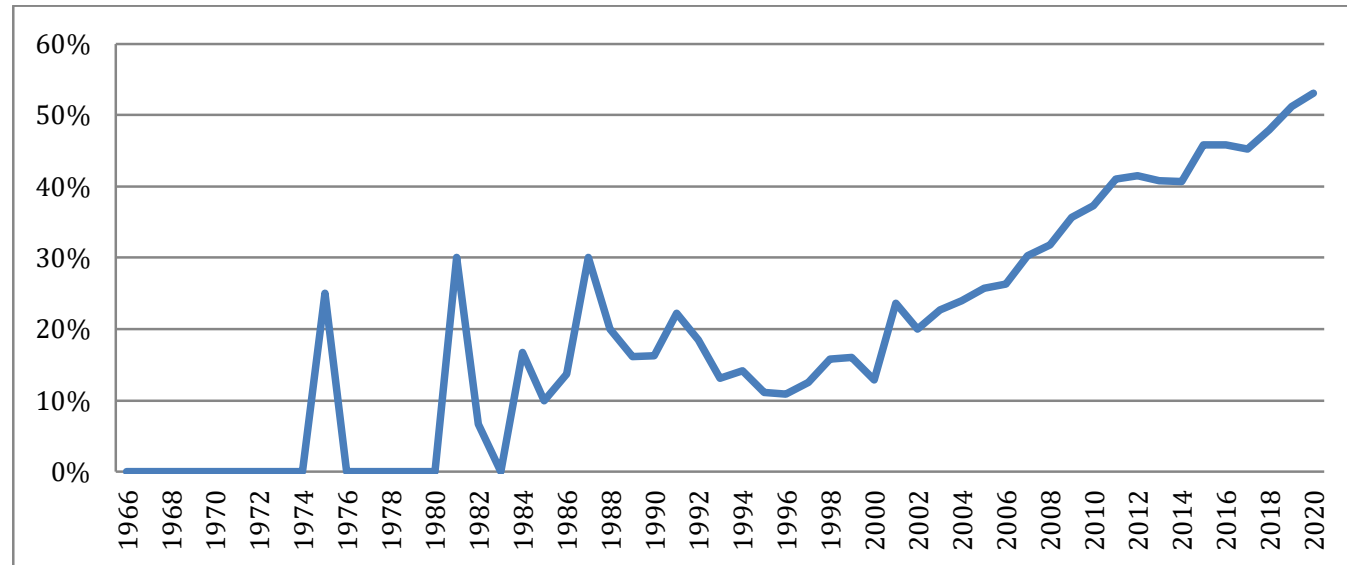

Fuente: Elaboración propia. 
La figura 14 muestra la evolución de este indicador desagregado para las tres categorías analizadas a partir de mediados de los noventa, años en los que el volumen de publicaciones disponibles es mayor, generando menos dispersión lo que permite apreciar mejor las tendencias. Como se puede observar, la categoría de Economía tiene un comportamiento ligeramente diferente a las otras dos, presentando siempre valores inferiores, aunque comparte la clara tendencia creciente a favor de la firma por orden de contribución.

\section{FIGURA 14. EVOLUCIÓN DEL PORCENTAJE DE ARTÍCULOS DENTRO DE SU CATEGORÍA FIRMADOS POR CONTRIBUCIÓN EN BUSINESS, ECONOMIC Y MANAGEMENT. PERIODO 1.995-2.020}

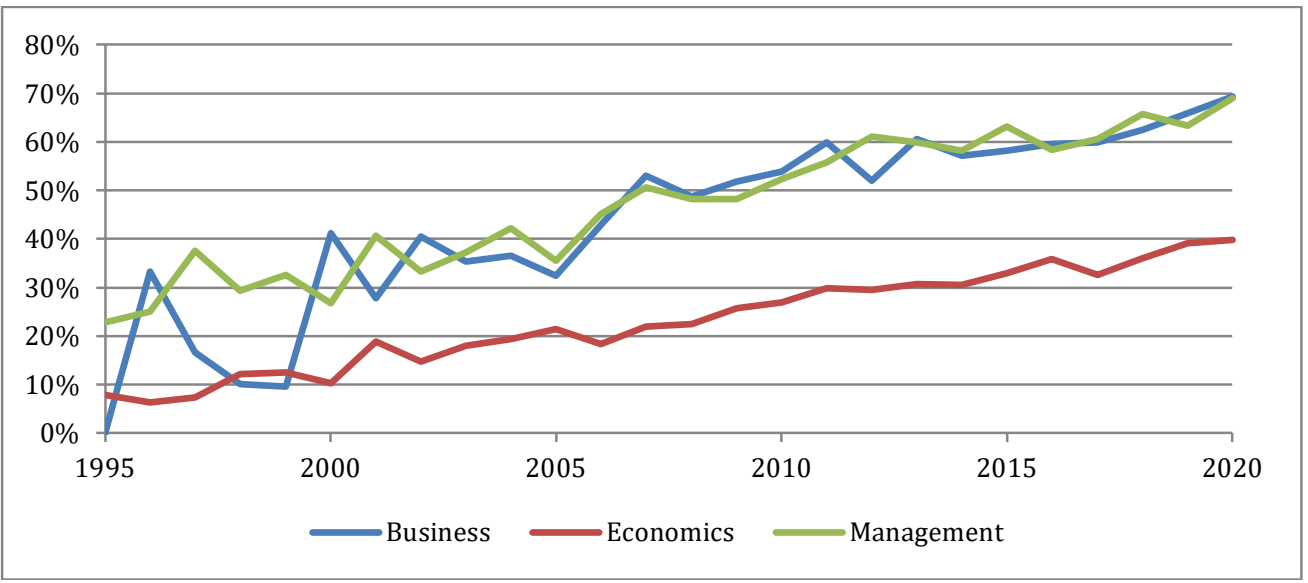

Fuente: Elaboración propia.

A continuación, se ha evaluado si los hábitos relativos al orden de firma se producen en cualquier tipo de investigación o tienen un comportamiento diferente en la investigación que se realiza con colaboración internacional. La figura 15 muestra esta relación y, como es fácil observar, en los trabajos que participan más países es más habitual la firma por orden de contribución (41,47 por cien de media) que en aquellos artículos en los que sólo participan investigadores españoles que suponen el 36,74 por cien.

\section{FIGURA 15. PORCENTAJE DE ARTÍCULOS FIRMADOS POR ORDEN DE CONTRIBUCIÓN EN RELACIÓN AL NÚMERO DE PAÍSES PARTICIPANTES}

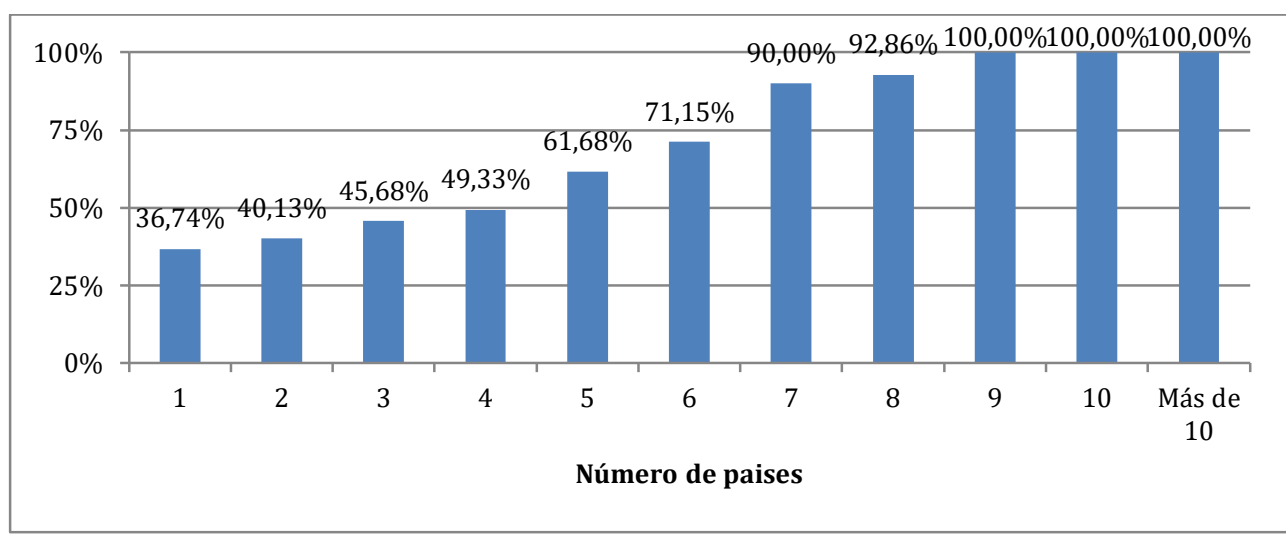

Fuente: Elaboración propia. 
Por último, se ha analizado en qué medida, en los artículos que no se firman por orden alfabético, el primer autor es más relevante que el último o viceversa, y cómo ha evolucionado este comportamiento. Para medir la relevancia científica se calculó el índice h de cada autor en la WoS y se comparó este indicador entre los autores que ocupan la primera y última posición. Así, se observó que en el 42,13 por cien de los artículos firmados por orden de contribución el primer autor presentaba un índice $\mathrm{h}$ mayor. Por otro lado, en el 38,96\% de los casos es el último autor el más relevante. Estos resultados podrían indicar que, en el ámbito de Ciencias Económicas y Empresariales en nuestro país, en términos generales, el autor más relevante científicamente ha impuesto su primera posición en el orden de firma. En cualquier caso, este comportamiento parece no haber sido siempre así, como se puede observar en la figura 16, en la que se representan estos indicadores a partir de principios de los noventa, por haber menor dispersión y así facilitar la visualización. Como se puede observar, la brecha se ha ido reduciendo, hasta llegar a la situación actual en la que el porcentaje de artículos de investigación en los que el autor más relevante científicamente firma en primer lugar es menor que cuando firma en último lugar.

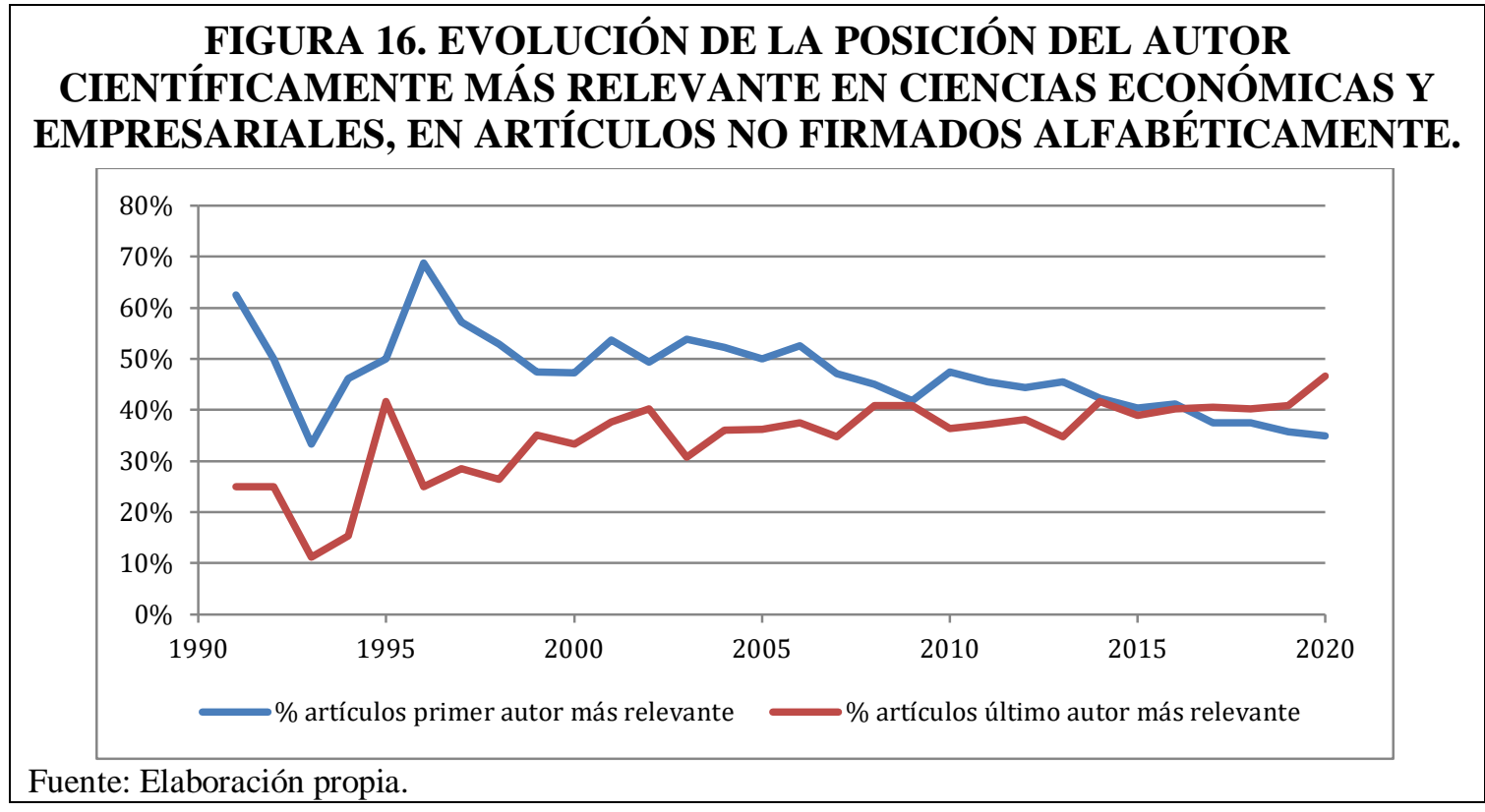

\subsection{Cuestión de investigación 3}

Para finalizar, se ha analizado el papel del autor para la correspondencia que, cada vez más, se está teniendo en cuenta para la evaluación de los méritos de investigación. En la colección de trabajos analizada, la WoS comienza a reportar datos sobre esta figura a partir de 1977. Así, de los 25.053 artículos analizados se pudo extraer esta información en 24.742.

El primer aspecto analizado fue la posición que ocupa el autor para la correspondencia en el orden de firma, y se observó que en el 77,19 por cien de los artículos en Ciencias Económicas y Empresariales es el primer autor el que figura como autor para la correspondencia. Al desagregar la colección de artículos con esta información por categorías, se observa como en Economía este porcentaje (76,67 por cien) es ligeramente inferior al observado en Business (80,77 por cien) y Management (77,30 por cien). 
La figura 17 muestra la evolución de este comportamiento desde 1.977, año del a partir del cuál los artículos analizados muestran esta información. Como se puede observar existe una clara tendencia decreciente, a partir de mediados de los noventa, a que la figura del autor para la correspondencia deje de coincidir con la del primer autor. Este comportamiento puede ser la respuesta de los investigadores a repartir de cierta manera los méritos de la investigación desde el momento en que la figura del autor para la correspondencia pasa a ser valorado como un mérito adicional.

\section{FIGURA 17. EVOLUCIÓN DEL \% DE ARTÍCULOS EN LOS QUE EL AUTOR PARA LA CORRESPONDENCIA COINCIDE CON EL PRIMER AUTOR}

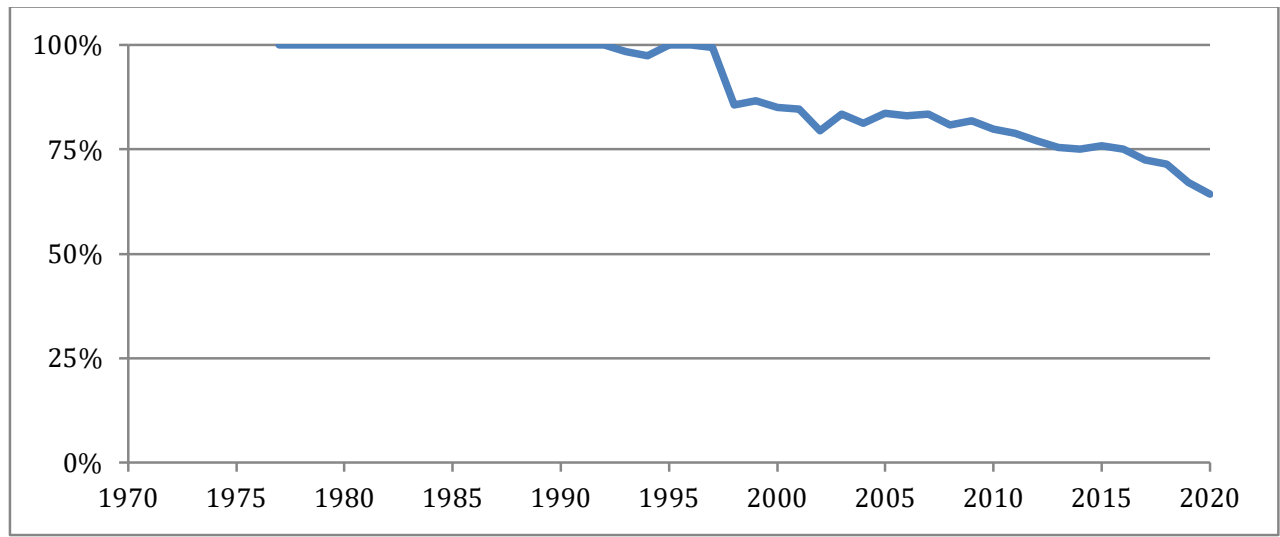

Fuente: Elaboración propia.

Al desagregar por categorías ${ }^{7}$, no se observan grandes diferencias entre las tres analizadas, es más, se observa cierta convergencia entre ellas (figura 18).

\section{FIGURA 18. EVOLUCIÓN DEL \% DE ARTÍCULOS EN LOS QUE EL AUTOR PARA LA CORRESPONDENCIA COINCIDE CON EL PRIMER AUTOR, POR CATEGORÍAS WOS}

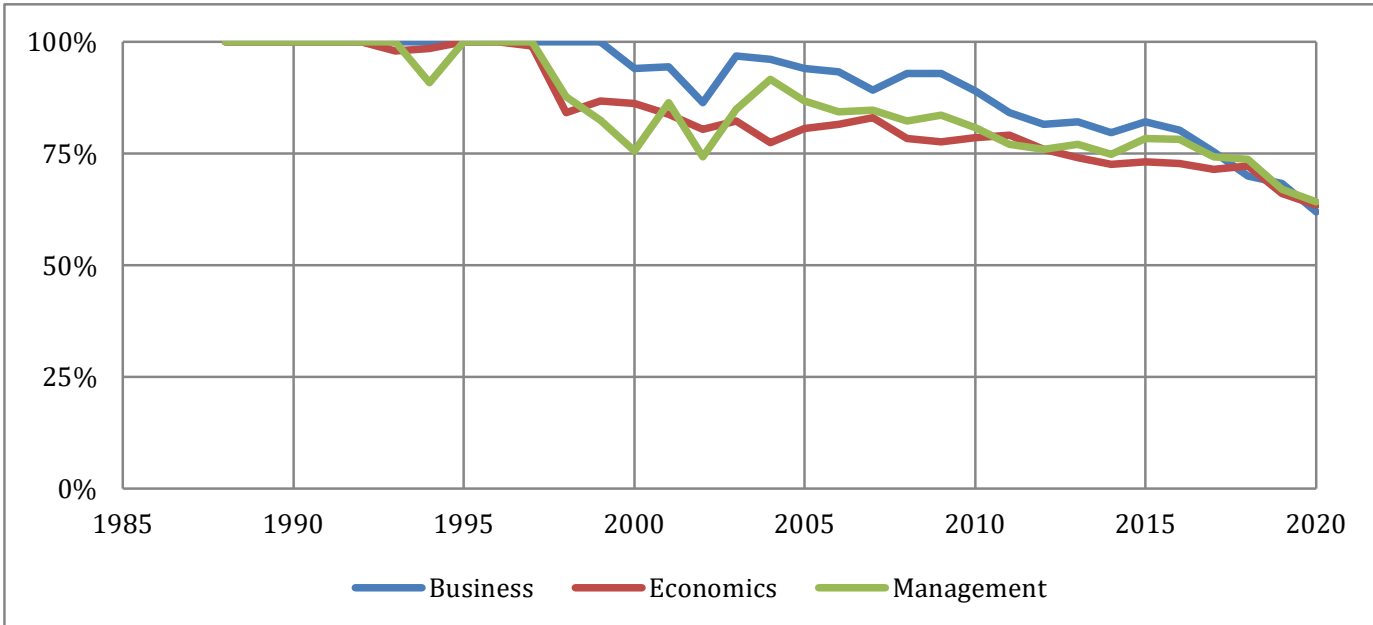

Fuente: Elaboración propia.

\footnotetext{
${ }^{7}$ Se representa desde 1988, primer año en el que no hay ninguna de las tres categorías sin datos del autor para la correspondencia.
} 
Ha parecido interesante analizar también si este comportamiento es diferente en el caso de las publicaciones de carácter exclusivamente nacional frente a aquellas en las que participan investigadores de otros países. La figura 19 muestra que también hay un comportamiento diferente en este aspecto, así, el porcentaje de artículos en los que la figura del autor por correspondencia coincide con la del primer autor en las investigaciones con participación internacional es, en promedio, del 73,03 por cien, mientras que en las investigaciones exclusivamente con participación española es del 80,14 por cien.

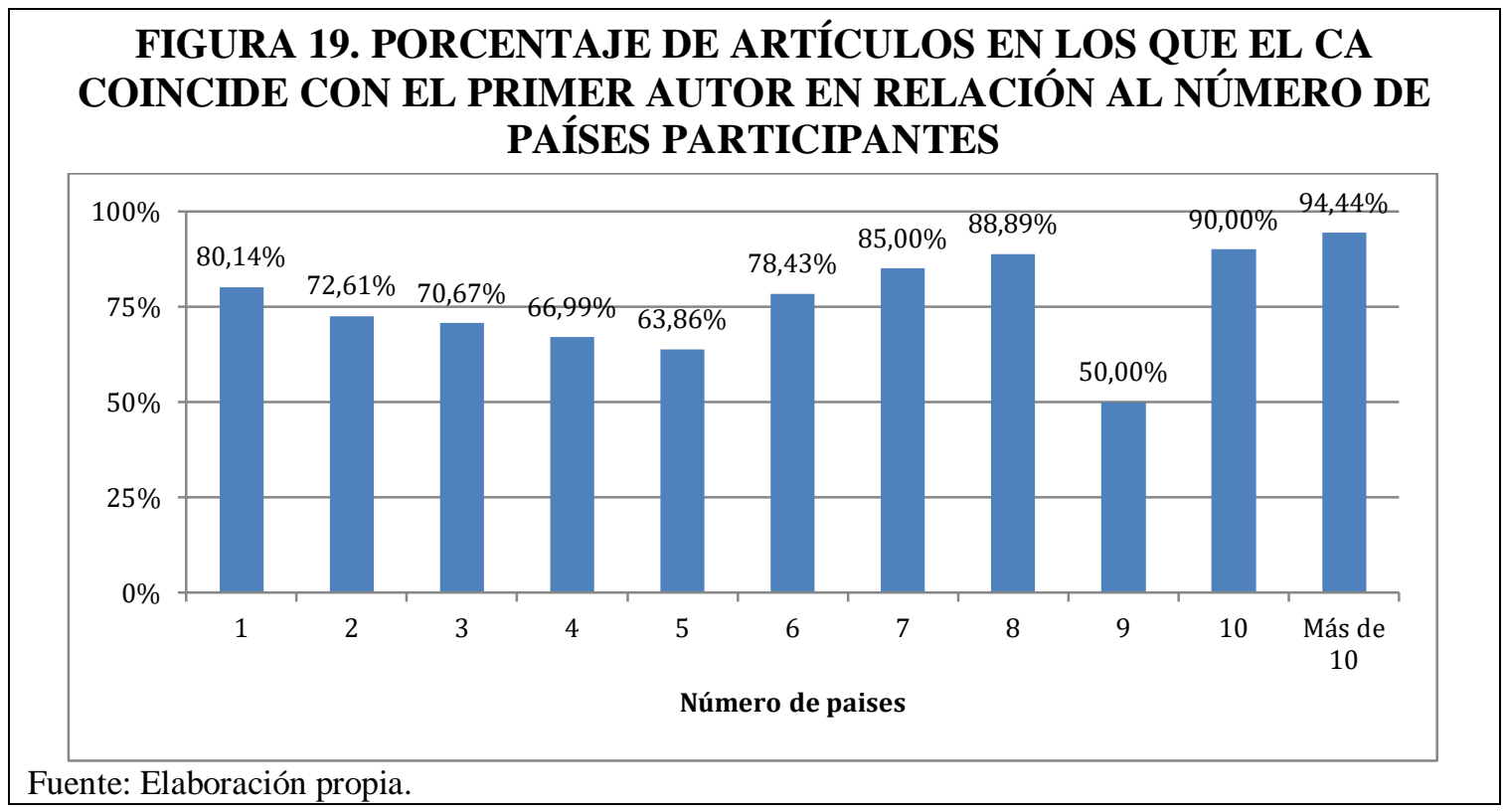

\section{CONCLUSIONES}

El análisis bibliométrico realizado en este trabajo sobre una muestra representativa de la investigación española en Ciencias Económicas y Empresariales ha permitido caracterizar los patrones de autoría y colaboración en artículos indexados en las revistas de mayor impacto y prestigio internacional, así como comprender su evolución a lo largo de los últimos cincuenta años. De los resultados y principales hallazgos conviene destacar las siguientes conclusiones e implicaciones prácticas.

En primer lugar, los investigadores españoles en Ciencias Económicas y Empresariales están haciendo un esfuerzo extraordinario por publicar sus resultados de investigación en revistas indexadas en la WoS, como así lo demuestra la creciente participación relativa en la producción total del campo en esta base de datos de reconocido prestigio internacional. En poco más de veinte años, se ha pasado de tener una participación insignificante en la producción internacional a casi el 5\% que representa la de nuestros investigadores en la actualidad.

En segundo lugar, se consolida la percepción de que la Ciencia actual necesita hacerse en colaboración, como así lo demuestra que a lo largo de los últimos cincuenta años casi el 85 por cien de los artículos se han firmado por más de un autor, en una tendencia claramente creciente, que alcanza los valores máximos de la serie en estos los últimos años, superando claramente el 90 por cien. Refuerza este hallazgo el hecho de que el número medio de autores por artículo también ha crecido de forma clara, superando a los 3 autores promedio por artículo en los últimos años. 
Se ha observado también una clara relación positiva entre número de autores por artículo e impacto que muestra claramente que a medida que crece el número de autores aumenta el número de citas recibido. Este fenómeno puede ser debido a la mayor visibilidad e influencia que puede ejercer un mayor tamaño del equipo de investigadores.

Además de lo anterior, es necesario reforzar el convencimiento de que la colaboración debe traspasar fronteras. La colaboración internacionalización se traduce en equipos más complejos y, como es lógico, en el aumento del número medio de autores por artículo, pero al mismo tiempo, como los resultados de este trabajo han puesto de manifiesto, se observa que genera más impacto académico, lo que refuerza la orientación y el necesario esfuerzo actual de las políticas públicas de fomento de la investigación supranacional en esta dirección.

En tercer lugar, a lo largo de los últimos cincuenta años el modelo de firma por contribución se ha impuesto claramente a la firma por orden alfabético en el ámbito de las Ciencias Económicas y Empresariales en nuestro país y esto es, especialmente patente, en los trabajos que suponen colaboración internacional. Así, en la actualidad, ya son más de la mitad de los artículos indexados en revistas JCR los que se firman por orden de aportación, siguiendo una clara tendencia creciente. Entre las razones que pueden explicar este comportamiento podría estar el reconocimiento implícito que los sistemas de incentivos y acreditación de nuestro país están otorgando a la posición que ocupan los autores en cada aportación y es coherente con la conocida idea de que a medida que se va ganando experiencia, responsabilidad y relevancia científica se tiende a ir ocupando posiciones más a la derecha.

En cuarto lugar, se ha observado una clara tendencia a que la figura del primer autor y el autor para la correspondencia cada vez coinciden menos. Así, en la actualidad este porcentaje se aproxima al 60 por cien, cuando hace apenas veinticinco años era casi del 100 por cien. Una posible explicación de esta tendencia puede ser que la figura del autor para la correspondencia empieza a ser reconocido como mérito adicional en los sistemas de acreditación y de incentivos en España, como pasa en otras disciplinas de carácter más experimental y que refleja, en cierto modo, un comportamiento interno en los equipos de autores orientado a reconocer y compartir el mérito derivado de la coordinación del equipo en la redacción y maquetación del manuscrito, y de éste con los editores en el proceso de envío, revisión y edición final.

Por último, en todos los indicadores analizados se ha observado un comportamiento paralelo en las tres disciplinas analizadas de forma desagregada, si bien se observan diferencias significativas. Así, de la comparación de la categoría Economic con las de Business y Management, se ha observado que tanto el número medio de autores por artículo como el porcentaje de artículos que se firman en colaboración, son menores en la primera que en las otras dos. Además de lo anterior, también es considerablemente menor el porcentaje de artículos que se firma por orden de contribución o, dicho de otro modo, es más habitual el uso del orden alfabético. Por el contrario, el papel del autor para la correspondencia se ha observado análogo en todas las categorías.

Los resultados obtenidos tienen numerosas implicaciones para el sistema académico español. En primer lugar, los sistemas de incentivos y acreditación nacional están empujando a los investigadores de forma inevitable a publicar en revistas indexadas de alto prestigio internacional para poder progresar, al reconocer de manera privilegiada este tipo de aportaciones, descuidando, en muchas ocasiones, resultados de investigación relevantes que son publicadas en otro tipo de fuentes. Es mas, esta 
obligación de publicar en revistas JCR para optar a evaluaciones positivas está llevando a muchos investigadores noveles y a otros no tanto, a tomar atajos que podrían considerarse poco éticos. Así, por ejemplo, se observan publicaciones en revistas que estando indexadas en JCR informan de plazos desde el envío hasta la publicación final que son sospechosos de tener procesos de revisión poco o nada exigentes y que, en la mayoría de los casos, exigen importantes cantidades de dinero por la publicación. Nada tiene esto que ver con las revistas tipo Open Access que de forma clara y legítima cobran por la edición y publicación, pero tienen unos sistemas de evaluación anónimos por pares con la máxima garantía y exigencia.

Por otro lado, aunque el número medio de autores por artículo ha crecido sin parar en los últimos años, no se ha observado un claro fenómeno de hiperautoría, quizás frenado también por el reconocimiento explícito de las agencias de evaluación de que un número elevado de autores puede penalizar la puntuación. En este sentido, se hace imprescindible utilizar el criterio de productividad fraccionaria en la evaluación de las aportaciones. En cualquier caso, todo esto no exime a los investigadores de ser exigentes y vigilantes en aplicar las normas éticas de quién debe y quién no debe firmar un artículo de investigación.

De todo lo anterior surge una buena oportunidad para justificar la creación de comités éticos en el seno de las universidades que aseguren el juego limpio entre sus científicos y que sean vigilantes con la calidad real de la investigación que se realiza y publica.

Para finalizar, el hecho de que el modelo de firma por orden de contribución sea cada vez más habitual, sobre todo en trabajos que suponen colaboración internacional, y el papel tan relevante que juega el autor para la correspondencia en el proceso de publicación, exigen que la figura del primer autor y del autor para la correspondencia deban ser claramente reconocidos en los criterios de evaluación. Además de lo anterior, las diferencias observadas entre Economía y Empresa también se debería traducir en un tratamiento diferenciado en los sistemas de incentivos y acreditación. Para ello se hace necesario profundizar en el conocimiento y explicación de estas diferencias.

Otras líneas de investigación futura exigen la recopilación de información de otras bases de datos, como Scopus, ABI/Inform, Dialnet, Econlit, JSTOR, REPEC, REDALYC, SciELO, etcétera, dado que la colección de artículos analizada en este trabajo solo representa una pequeña parte de la investigación que se realiza en el ámbito de las Ciencias Económicas y Empresariales en España. Además de lo anterior, dado que el campo de las Ciencias Económicas y Empresariales es muy amplio, sería necesario profundizar más en el análisis de las diferencias entre sus áreas de conocimiento como Economía Aplicada, Organización de Empresas, Finanzas y Contabilidad o Marketing, por ejemplo, con los indicadores utilizados y algunos otros que permitan caracterizar el fenómeno de la colaboración y la coautoría de manera más completa.

Por último, a la vista de los resultados obtenidos y de la evolución observada en el campo, mostrar el convencimiento de que el diseño de los criterios de evaluación en los sistemas de promoción y acreditación se traducen en un claro proceso adaptativo en el comportamiento de todos los actores que forman parte del sistema nacional de ciencia y conocimiento de nuestro país y que, por otro lado, con el paso del tiempo se hace necesario que los responsables del diseño de estos sistemas revisen cada cierto tiempo esos criterios y los adapten a las singularidades de cada área de conocimiento. 


\section{BIBLIOGRAFÍA}

Abramo, G., D’Angelo, C. A., \& Di Costa, F. (2019). The collaboration behavior of top scientists. Scientometrics, vol. 118, n1 1, pp. 215-232. https://doi.org/10.1007/s11192-018-2970-9.

Abramo, G.; d'Angelo, C.A.; Rosati, F. (2019). Measuring institutional research productivity for the life sciences: the importance of accounting for the order of authors in the byline. Scientometrics. 2013; n 97, pp. 779-95.

Avula, J.; Avula, H. (2015). Authors, authorship order, the moving finger writes. $J$ Indian Soc Periodontol Jun; vol. 19, $\mathrm{n}^{\circ}$ 3, pp. 258-62.

Bhandari, M.; Guyatt, G. H.; Kulkarni, A. V., Devereaux, P. J.; Leece, P.; Bajammal, S.; Busse, J. W. (2014). Perceptions of authors' contributions are influenced by both byline order and designation of corresponding author. Journal of Clinical Epidemiology, vol. 67, nº 9, pp. 1049-1054. 10.1016/j.jclinepi.2014.04.006.

Brand, A., Allen, L., Altman, M., Hlava, M., \& Scott, J. (2015). Beyond authorship: attribution, contribution, collaboration, and credit. Learned Publishing, vol. 28, $\mathrm{n}^{\mathrm{o}}$ 2, pp. 151-155.

Brewis, J. (2018). On interference, collegiality and co-authorship: Peer review of journal articles in management and organization studies: The interdisciplinary journal of organization, theory and society the interdisciplinary journal of organization, theory and society. Organization, vol. 25, $\mathrm{n}^{\circ}$ 1, pp. 21-41.

Cainelli, G., Maggioni, M.A., Uberti, T.E., de Felice, A. (2015). The strength of strong ties: How co-authorship affect productivity of academic economists?. Scientometrics, $\mathrm{n}^{\circ}$ 102, pp. 673-699.

Cronin, B. (2001). Hyperauthorship: A postmodern perversion or evidence of a structural shift in scholarly communication practices? Journal of the American Society for Information Science and Technology, vol. 52, $\mathrm{n}^{\mathrm{o}} 7$, pp. 558-569. https://doi.org/10.1002/asi.1097.

Cutas, D. and Shaw, D. (2015) Writers blocked: on the wrongs of research coauthorship and some possible strategies for improvement. Science and Engineering Ethics, vol. 21, no 5, pp. 1315-1329.

De Filippo, D., Morillo, F., \& Fernandez, M. T. (2008). Indicators of scientific collaboration between CSIC and Latin America through international databases. Revista Española de Documentación Científica, vol. 31, n 1, pp. 66-84.

Duffy, M. A. (2017). Last and corresponding authorship practices in ecology. Ecology and Evolution, vol. 7, $\mathrm{n}^{\circ}$ 21, pp. 8876-8887. 10.1002/ece3.3435.

Endenich, C.; Trapp, R. (2016). Cooperation for Publication? An Analysis of Coauthorship Patterns in Leading Accounting Journals. European Accounting Review, 2016, vol. 25, nº. 3, pp. 613-633,

Fox, C. W., Ritchey, J. P., \& Paine, C. (2018). Patterns of authorship in ecology and evolution: First, last, and corresponding authorship vary with gender and geography. Ecology and evolution, vol. 8, $\mathrm{n}^{\mathrm{o}}$ 23, pp. 11492-11507. Glanzel y Schubert, 2004.

Glänzel, W. (2001). Coauthorship patterns and trends in the sciences (1980-1998): A bibliometric study with implications for database indexing and search strategies. Library Trends, vol. 50, no 3, pp. 461-473.

González Alcaide, G., \& Ferri, J. G. (2014). La colaboración científica: principales líneas de investigación y retos de futuro; Scientific collaboration: main research lines and future challenges. Revista Española de Documentación Científica, $\begin{array}{llllll}\text { Octubre-Diciembre } \quad 2014, & \text { vol. } \quad 37, & n^{\circ} & 4, & \text { e062. }\end{array}$ 
https://doi.org/10.3989/redc.2014.4.1186.

González-Alcaide, G., Park, J., Huamaní, C., \& Ramos, J. M. (2017). Dominance and leadership in research activities: Collaboration between countries of differing human development is reflected through authorship order and designation as corresponding authors in scientific publications. PloS one, vol. 12, $\mathrm{n}^{\mathrm{o}} 8$, e0182513Helgesson, 2020.

Helgesson, G; Eriksson, S. (2019) Authorship order. Learned Publishing, vol. 32, n 2, pp. 106-112

Jin, J. C. (2019). Research productivity in business and economics: South korea, 19902016*. East Asian Economic Review, vol. 23, n 1, pp. 89-107. Katsouyanni, 2008.

Koseoglu, Mehmet Ali (2016). Growth and structure of authorship and co-authorship network in the strategic management realm: Evidence from the Strategic Management Journal, BRQ Business Research Quarterly, vol. 19, n 3, pp. 153170.

Larivière, V., Haustein, S., \& Mongeon, P. (2015). The oligopoly of academic publishers in the digital era. PLoS One, vol. 10, $\mathrm{n}^{\circ}$ 6, e0127502.

Madiba, T. E., and Dhai, A. (2006). Addressing authorship disputes. S. Afr. Med. J. n ${ }^{\circ}$ 96, pp. 49-50.

Manton, E. J., English, D. (2008) 'An Empirical Study of Gift Authorships in Business Journals', The Journal of Education for Business, vol. 83, $n^{0}$ 5, pp. 283-7.

Manton, E. J.; English, D. E. (2007). The trend toward multiple authorship in business journals. Journal of Education for Business, vol. 82, n 3, pp. 164-8.

Marušić, A.; Bošnjak, L.; Jerončić, A. (2011). A Systematic Review of Research on the Meaning, Ethics and Practices of Authorship across Scholarly Disciplines, PLoS One, vol. 6, $\mathrm{n}^{\circ} 9$.

Mattsson P, Sundberg CJ, Laget P. (2011). Is correspondence reflected in the author position? A bibliometric study of the relation between corresponding author and byline position. Scientometrics, no 87, pp. 99-105. doi: 10.1007/s11192-010-03109.

Mishra, R. \& Ramesh, D.B. (2018). A study of authorship pattern and degree of collaboration in business research during 1998-2017. International Journal of Information Dissemination and Technology, vol. 8, n ${ }^{\circ}$ 3, pp. 150-153.

Mo, Z., Hui-Zhen Fu, \& Yuh-Shan Ho. (2018). Highly cited articles in wind tunnelrelated research: A bibliometric analysis. Environmental Science and Pollution Research International, vol. 25, $\mathrm{n}^{\circ}$ 16, pp. 15541-15553.

Nowell, C., \& Grijalva, T. (2011). Trends in co-authorship in economics since 1985. Applied Economics, vol. 43, no 28, pp. 4369.

Pfleegor, A. G., Katz, M., \& Bowers, M. T. (2019). Publish, perish, or salami slice? authorship ethics in an emerging field: JBE JBE. Journal of Business Ethics, vol. 156, $\mathrm{n}^{\circ} 1$, pp. 189-208.

Rath, K, and K Wohlrabe (2016), "Recent trends in co-authorship in economics: evidence from RePEc”, Applied Economics Letters, vol. 23, n 12, pp. 897-902.

Ruíz-Pérez, R., Marcos-Cartagena, D., \& Delgado López-Cózar, E. (2014). La autoría científica en las áreas de ciencia y tecnología. Políticas internacionales y prácticas editoriales en las revistas científicas españolas. Revista española de Documentación Científica, vol. 37, nº 2, e049.

Safa, M. (2012). Ethics in publication: To be practices or not to be. International Journal of Business and Management Services, $\mathrm{n}^{\circ}$ 5, 77-84.

Schubert T, Sooryamoorthy R. Can the centre-periphery model explain patterns of international scientific collaboration among threshold and industrialised countries? 
The case of South Africa and Germany. Scientometrics. 2010; $\mathrm{n}^{\circ}$ 83, pp.181-203.

Smith E and Williams-Jones B (2012) Authorship and responsibility in health sciences research: a review of procedures for fairly allocating authorship in multi-author studies. Science and Engineering Ethics, vol. 18, n 2, pp. 199-212.

Smith, E. (2017). A theoretical foundation for the ethical distribution of authorship in multidisciplinary publications. Kennedy Institute of Ethics Journal, vol. 27, $\mathrm{n}^{\circ} 3$, pp. 371-411.

Sundling, P. (2017), "The many hands of science: commonalities and differences in the research contributions of authors and subauthors", Aslib Journal of Information Management, vol. 69, $\mathrm{n}^{\circ}$. 5, pp. 591-606

Wang, X., Xu, S., Wang, Z., Peng, L., \& Wang, C. (2013). International scientific collaboration of China: collaborating countries, institutions and individuals. Scientometrics, vol. 95, no 3, pp. 885-894. https://doi.org/10.1007/s11192-0120877-4.

Wardil, L., \& Hauert, C. (2015). Cooperation and coauthorship in scientific publishing. Physical Review E, vol. 91, nº 1. https://doi.org/10.1103/PhysRevE.91.012825.

Wuchty, S., Jones, B. F., \& Uzzi, B. (2007). The increasing dominance of teams in production of knowledge. Science, vol. 316, n 5827, pp. 1036-1039.

Zutshi, A., McDonald, G., \& Kalejs, L. (2012). Challenges in collaborative writing: Addressing authorship attribution. European Business Review, vol. 24, n ${ }^{\circ}$, pp. 28-46. 